\title{
Multidisciplinary approach to constrain kinematics of fault zones at shallow depths: a case study from the Cameros-Demanda thrust (North Spain)
}

\author{
A. M. Casas-Sainz ${ }^{1}$ T. Román-Berdiel ${ }^{1}$ B. Oliva-Urcia ${ }^{2}$ C. García-Lasanta ${ }^{1}$. \\ J. J. Villalaín ${ }^{3} \cdot$ L. Aldega ${ }^{4} \cdot$ S. Corrado ${ }^{5}$ C. Caricchi ${ }^{5} \cdot$ C. Invernizzi ${ }^{6} \cdot$ M. C. Osácar ${ }^{1}$
}

Received: 18 January 2016 / Accepted: 1 June 2016

(C) Springer-Verlag Berlin Heidelberg 2016

\begin{abstract}
Thrusting at shallow depths often precludes analysis by means of structural indicators effective in other geological contexts (e.g., mylonites, sheath folds, shear bands). In this paper, a combination of techniques (including structural analysis, magnetic methods, as anisotropy of magnetic susceptibility and paleomagnetism, and paleothermometry) is used to define thrusting conditions, deformation, and transport directions in the Cameros-Demanda thrust (North Spain). Three outcrops were analyzed along this intraplate, large-scale major structure having $150 \mathrm{~km}$ of outcropping length, $30 \mathrm{~km}$ of maximum horizontal displacement, and $5 \mathrm{~km}$ of vertical throw. Results obtained by means of the different techniques are compared with data derived from cross sections and stratigraphic analysis. Mixed-layer illite-smectite and vitrinite reflectance indicating deep diagenetic conditions and mature stage of hydrocarbon generation suggests shallow depths during
\end{abstract}

T. Román-Berdiel

mtdjrb@unizar.es

A. M. Casas-Sainz
acasas@unizar.es
B. Oliva-Urcia
belen.oliva@uam.es
C. García-Lasanta
lasanta@unizar.es
J. J. Villalaín
villa@ubu.es
L. Aldega
luca.aldega@uniroma1.it
S. Corrado
sveva.corrado@uniroma3.it
C. Caricchi
chiara.caricchi@gmail.com

deformation, thus confirming that the protolith for most of the fault rocks is the footwall of the main thrust. Kinematic indicators (foliation, S/C structures, and slickenside striations) indicate altogether a dominant NNW movement of the hanging wall in the western zone and NE in the eastern zone of the thrust, thus implying strain partitioning between different branches of the main thrust. The study of AMS in fault rocks (nearly 400 samples of fault gouge, breccia, and microbreccia) indicates that the strike of magnetic foliation is oblique to the transport direction and that the magnetic lineation parallelizes the projection of the transport direction onto the $k_{\max } / k_{\text {int }}$ plane in sites with strong shear deformation. Paleomagnetism applied to fault rocks indicates the existence of remagnetizations linked to thrusting, in spite of the shallow depth for deformation, and a strong deformation or scattering of the magnetic remanence vectors in the fault zone. The application of the described techniques
C. Invernizzi

chiara.invernizzi@unicam.it

M. C. Osácar

cinta@unizar.es

1 Departamento de Ciencias de la Tierra, Universidad de Zaragoza, Pedro Cerbuna 12, 50009 Saragossa, Spain

2 Departamento de Geología y Geoquímica, Universidad Autónoma de Madrid, Madrid, Spain

3 Laboratorio de Paleomagnetismo, Departamento de Física, Universidad de Burgos, Burgos, Spain

4 Dipartimento di Scienze della Terra, Sapienza Università di Roma, Rome, Italy

5 Dipartimento di Scienze, Università Roma Tre, Rome, Italy

6 Scuola di Scienze e Tecnologie, Sezione Geologia, Università di Camerino, Camerino, Italy 
and consistency of results indicate that the proposed multidisciplinary approach is useful when dealing with thrusts at shallow crustal levels.

Keywords Intraplate thrusting - Fault rock . Cameros-Demanda thrust $\cdot$ Transport direction . Magnetic techniques · Paleothermometry

\section{Introduction}

Intraplate thrusts are responsible for the uplift of large areas of the continental crust and the re-arrangement of continental segments through significant horizontal displacements (e.g., Smithson et al. 1978; Erslev 1986; Steidtmann and Middleton 1991; Avouac et al. 1993; Zheng et al. 1998; Kley and Voigt 2008; Fernández-Lozano et al. 2011; Coubal et al. 2014; Seillé et al. 2015 and references therein). The accurate determination of transport directions and displacements of intraplate thrusts is a major issue in plate tectonics reconstruction, especially when displacements are relevant in relation to plate size, as it occurs in Iberia (see De Vicente 2004; Fernández-Lozano 2012 and references therein). Important points when dealing with intraplate thrusts are the total displacement and the depth at which deformation took place, but other equally crucial issues are their transport direction and deformations associated with fault rocks in the thrust zone (Ramsay 1981; Ramsay et al. 1983; Lister and Snoke 1984; Grasemann et al. 1999; Bigi 2006; Alsop 2009; Calamita et al. 2012, among others).

Because of its spectacular outcrop conditions, the Iberian Chain (N Spain) has been the subject of several works dealing with the kinematics of thrusts (Guimerà et al. 1995, 2004; Capote et al. 2002; Simón and Liesa 2011 and references therein). As some of these authors point out, apparent simple structures can show a complex kinematic history, conditioned by geometry of faults inherited from previous stages or syn-tectonic sedimentation (see also Barrier et al. 2002). As a consequence, several transport directions can be inferred from macro- and mesostructural indicators, related in turn with the complex compressional history of intraplate structures (Capote et al. 2002; De Vicente 2004; Liesa and Simón 2009).

Understanding the kinematics of thrusting involves the knowledge of thermal conditions and mechanical behavior of fault rocks associated with thrusting, together with the depth of thrusting and determination of the rock provenance (see, e.g., Yonkee et al. 1989; Fauconnier et al. 2014). In this sense, clay minerals and other paleothermometers as fluid inclusions and vitrinite reflectance have been proved as useful techniques for studying fault rocks (Vrolijk and Van der Pluijm 1999; Schleicher et al. 2012; Trincal et al. 2014). Reactions in clay minerals and organic matter are irreversible under normal diagenetic and anchizonal conditions, so that exhumed sequences generally retain indices and fabrics indicative of their maximum maturity and burial (Caricchi et al. 2015). Therefore, they can provide information on fluid circulation, water/rock ratio, and frictional heating (Balsamo et al. 2014). Magnetic methods and specifically anisotropy of magnetic susceptibility (AMS) and paleomagnetism have been applied to the study of fault rocks with different degrees of success (Hirono et al. 2006; Solum and van der Pluijm 2009; Mertainen and Karell 2012; Pomella 2014; Moreno et al. 2014). The quality of the obtained results is strongly dependent on the magnetic properties of materials, the type of fault rocks, and the number of samples used for determining the average magnetic foliation and lineation. In shear zones, the resultant maximum axis of the magnetic susceptibility ellipsoid is assumed to be parallel to the transport direction on C planes (see Parés and Van der Pluijm 2002), although case studies also indicate (1) intermediate orientations at the bisector between $\mathrm{S}$ and $\mathrm{C}$ planes (Aranguren et al. 1996) and (2) opposite geometrical relationships, with $k_{\max }$ perpendicular to the transport direction and, consequently, parallel to the intersection lineation between $\mathrm{C}$ and $\mathrm{S}$ planes (Oliva-Urcia et al. 2009; Ono et al. 2010). Because of these ambiguous relationships, it is extremely important to determine in each particular case the type of geometrical relationship between AMS and kinematic indicators both at the outcrop and microscopic scales (Debacker et al. 2004, 2010; Haerinck et al. 2015).

In this work, several techniques (AMS, paleomagnetism, $\mathrm{X}$-ray diffraction of clay minerals, and organic matter optical analyses) are applied to the study of a major thrust zone in the Iberian plate: the Cameros-Demanda thrust. This particular structure was responsible for the relative horizontal movement of about $30 \mathrm{~km}$ between the Ebro basin (the foreland basin to the Pyrenees) and the inner part of the Iberian plate, and for a vertical displacement of more than $5 \mathrm{~km}$, creating a major sedimentary continental trough fed by the hanging wall of the thrust during Cenozoic times (Casas and Faccenna 2001). In spite of its dimensions, the structure of the Cameros-Demanda thrust is relatively simple, having slight dip changes and lacking vertical-axis rotations (Villalaín et al. 2003; Casas et al. 2009). The complete sedimentary record at its footwall also permits dating and characterizing the stages of tectonic activity (MuñozJiménez and Casas-Sainz 1997). Furthermore, because of the good exposures of fault rocks linked to thrusting, the Cameros-Demanda thrust provides an ideal context for getting insights into intraplate thrust evolution. Results regarding boundary conditions of the shear zone (depth, temperature, transport direction) are compared and complemented with data inferred from classical geological techniques (geological mapping and cross sections, and relationships 
with syn-tectonic sediments) to finally obtain a reliable picture of thrusting conditions at the outcropping level.

\section{Geological setting}

The Cameros-Demanda thrust is one of the most outstanding geological structures of the Iberian plate. Its longitudinal development is about $150 \mathrm{~km}$ along an $\mathrm{E}-\mathrm{W}$ direction and accommodated $30 \mathrm{~km}$ of horizontal displacement and $5 \mathrm{~km}$ of vertical throw during Late Eocene-Miocene times (Casas-Sainz 1992; Mas et al. 1993; Guimerà et al. 1995; Muñoz-Jiménez and Casas-Sainz 1997). In its eastern segments, it results from the inversion of a normal fault bounding the Mesozoic Cameros Basin and an underlying shortcut thrust, whereas to the West the alpine thrust reactivated Variscan or Late Variscan structures in the Paleozoic basement (Sierra de la Demanda, Fig. 1). In this western sector (Fig. 1), the cartographic trace of the thrust shows an arcuate shape, with several along-strike changes, from ENE-WSW to E-W (Fig. 1), and NW-SE at the CamerosDemanda transition area. At the thrust front, two surfaces, branching at depth, can be recognized: the northernmost one superposes Triassic and Jurassic rocks on the Cenozoic at the footwall and the southern one puts Paleozoic rocks on the Mesozoic series.

In the eastern sector (Cameros Massif, Fig. 1), the Cameros-Demanda thrust shows three segments with NE-SW, $\mathrm{E}-\mathrm{W}$, and NW-SE strikes. Each portion is related to different dips of the thrust surface, shallower in the NE-SW segment $\left(12^{\circ}\right)$ and steeper $\left(30^{\circ}\right)$ in the NW-SE segment (Casas-Sainz and Simón-Gómez 1992). The overall geometry of the NE-SW segment is a continuous hanging wall flat of Upper Triassic gypsum and shales and Lower Jurassic limestones thrusting over a footwall ramp of horizontal Cenozoic conglomerates and sandstones. In the central sector, striking E-W, there are important outcrops of Upper Triassic shales and gypsum in the hanging wall of the main thrust, and local ramps related to inversion of extensional features inherited from the basinal stage (Casas-Sainz and Gil-Imaz 1998). Finally, in the easternmost sector, the Cameros-Demanda thrust shows two well-defined NW-SE segments, separated by an E-W-striking zone linked to a blind thrust at 1000-1500 m depth resulting from a shortcut during inversion through the Paleozoic basement. In the two NW-SE-striking segments, geometries are varied, showing hanging-wall flats, hanging-wall ramp anticlines, or ramps in both walls, related to the inversion of the normal faults bounding the Mesozoic Cameros Basin.

The kinematics of the Cameros thrust has been discussed in several papers (Guimerà et al. 1995; Casas-Sainz 1992, 1993; Casas-Sainz and Simón-Gómez 1992; Cortés Gracia and Casas-Sainz 1997). A dominant top-to-the-north movement is reported, but details about its kinematics are controversial, because of the divergence between the geometrical relationships inferred from the map view of the thrust and the kinematic indicators found in different parts of the thrust surface (see, e.g., Guimerà et al. 1995 and references therein). In this paper, from the application of physicochemical innovative techniques, we present a set of data that strive to shed new light to settle this controversy.

\section{Methods}

The three areas sampled for the application of the magnetic and paleothermometric techniques are located along the thrust front and show good exposures of the Cameros-Demanda thrust surface and the rocks at its footwall (Fig. 2): (1) Matute area, located in the NW-SE-striking segment in the Sierra de la Demanda sector; (2) Panzares area, in the NE-SW-striking segment and hanging wall flat in the Cameros Massif sector; and (3) Préjano area, in the $\mathrm{E}-\mathrm{W}$ segment where the outcropping thrust is the inverted normal fault responsible for the formation of the Cameros basin during the Mesozoic. Although most data come from locality (1), because its outcrop conditions allow sampling in different levels and a strict control of the structure of the hanging wall and the footwall, the different rock types, intensity of deformation, and structure found in these three localities are an added value for the understanding of the structure and kinematics of the Cameros-Demanda thrust as a whole.

\section{Structural analysis}

Common techniques for determining the transport direction of thrusts are derived from geometrical features, according to (1) the shape of thrusts in map view and the application of the bow and arrow rule (Elliot 1976), or (2) the crosscutting relationships in the hanging wall and the footwall (Alonso 1987; Pérez-Estaún et al. 1988). In particular tectonic contexts, as for example, basin inversion, the geometry of thrust surfaces can be controlled by other factors, such as faults inherited from the extensional stage or basement faults (i.e., De Graciansky et al. 1989), that alter the application of simple geometrical rules. Other kinematic indicators rely upon outcrop-scale shear criteria (Ramsay 1967; Ramsay and Huber 1987) or the microscopic studies of shear zones (Law 1998 in Snoke et al. eds.).

Geometrical relationships between thrust surfaces and the pre- and syn-tectonic sedimentary units at their hanging walls and footwalls were determined by means of detailed geological mapping and cross sections (Figs. 1, 2). Systematic measurements of bedding were also taken at the hanging wall of the thrust cropping out in the Préjano area and 

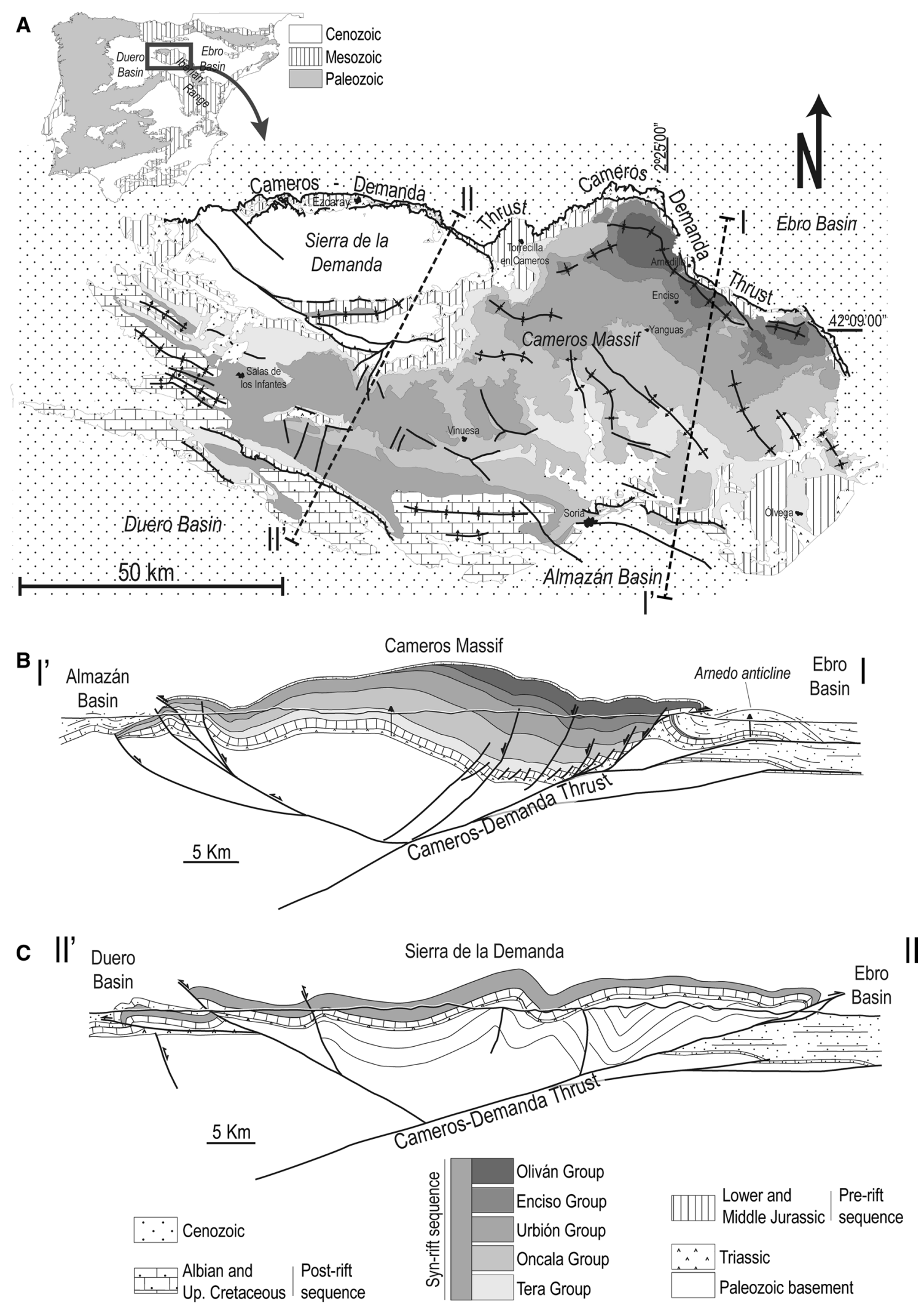

Fig. 1 Location of the Cameros-Demanda thrust within the Iberian Chain (modified from García-Lasanta et al. 2013) (a), and cross sections showing the overall structure of the thrust in the eastern (Cameros Massif, modified from Mata et al. 2001) (b), and western (Sierra de la Demanda) (c) areas. In the western area, the structure is defined by a basement thrusting and uplift, whereas to the east, it results from the inversion of the early cretaceous extensional basin and a shortcut thrust in the lower branch 


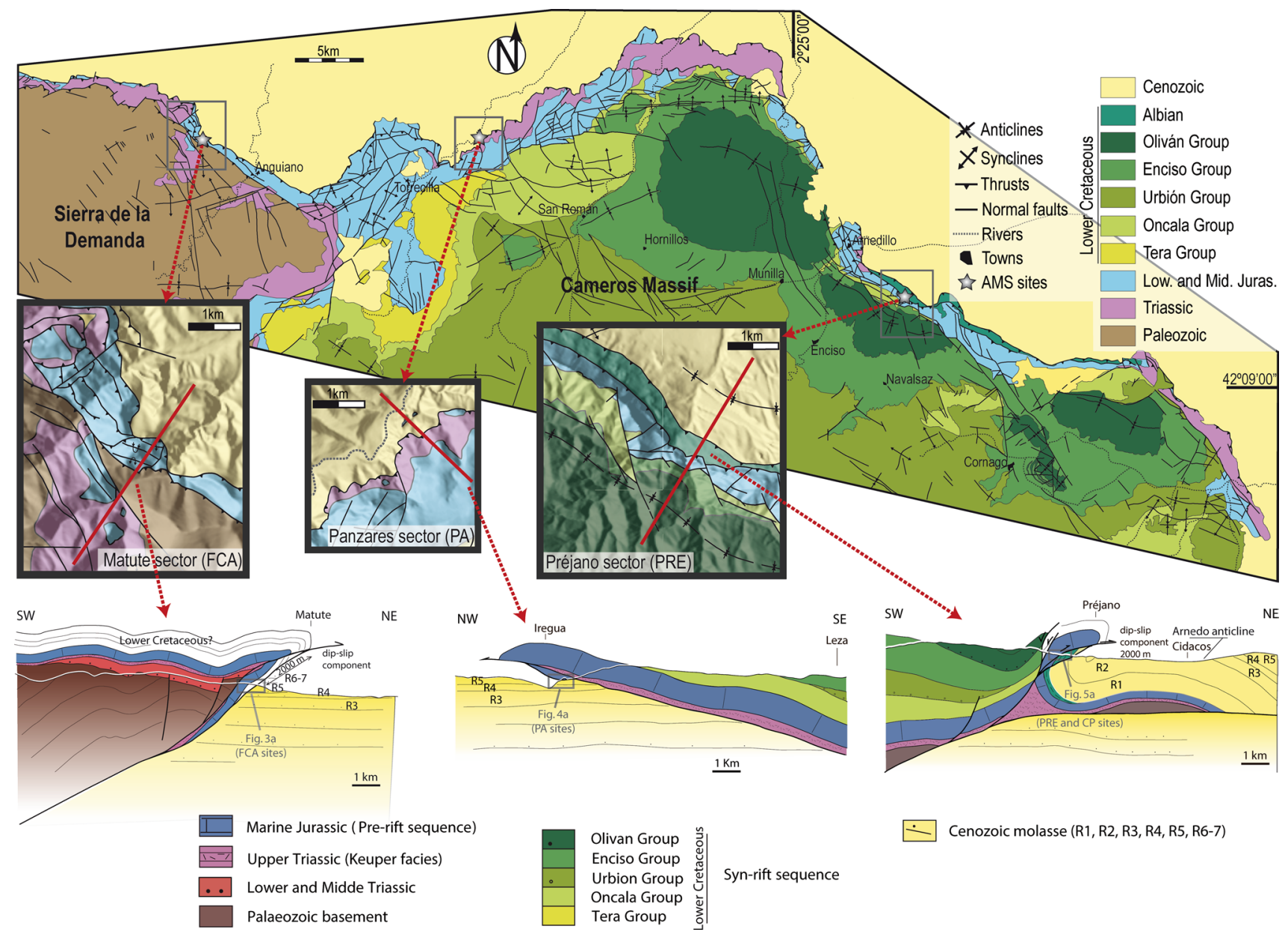

Fig. 2 Geological sketch of the Cameros Massif and the Cameros-Demanda thrust, with the location of the three studied sectors and cross sections showing the structure in each of the studied areas

at the intermediate slice of Mesozoic rocks in the Matute area. Analysis of shear zones included orientation of foliation and S/C structures at the outcrop scale and microscopic study of oriented thin sections obtained from specimens sampled for AMS studies.

\section{Paleothermometry}

Clay minerals in shales and sandstones undergo diagenetic and very low-grade metamorphic reactions in response to sedimentary and/or tectonic burial. One of the parameters generally used to provide information on thermal evolution of sedimentary successions is the variation in composition and stacking order of mixed-layered minerals. In particular, mixed-layer illite-smectite (I-S) is widely used in petroleum exploration as a geothermometer and, thus, as indicators of the thermal evolution of sedimentary sequences (Aldega et al. 2007, 2011; Bigi et al. 2009; Corrado et al. 2010; Pollastro 1990). The identified changes comply with the following scheme of progressive thermal evolution that has been correlated to the stages of hydrocarbon generation: di-smectite-disordered mixed layers (R0)-ordered mixed layers (R1 and R3)-illitedioctahedral K-mica (muscovite). XRD analyses were performed with a Scintag X1 X-ray system $(\mathrm{CuK} \alpha$ radiation) at $40 \mathrm{kV}$ and $45 \mathrm{~mA}$. Randomly oriented wholerock powders were run in the $2^{\circ}-70^{\circ} 2 \theta$ interval with a step size of $0.05^{\circ} 2 \theta$ and a counting time of 3 s per step. Oriented air-dried and ethylene-glycol solvated samples were scanned from $1^{\circ}$ to $48^{\circ} 2 \theta$ and from $1^{\circ}$ to $30^{\circ} 2 \theta$, respectively, with a step size of $0.05^{\circ} 2 \theta$ and a count time of $4 \mathrm{~s}$ per step. The illite and chlorite content in mixedlayer I-S and C-S was determined according to Moore and Reynolds (1997) using the delta two-theta method after decomposing the composite peaks between $9^{\circ}-10^{\circ}$ $2 \theta$ and $16^{\circ}-17^{\circ} 2 \theta$ for I-S and between $10^{\circ}-12.3^{\circ} 2 \theta$ and $25^{\circ}-26^{\circ} 2 \theta$ for $\mathrm{C}-\mathrm{S}$. The I-S ordering type (Reichweite parameter, R; Jagodzinski 1949) was determined by the position of the I001-S001 reflection between 5 and $8.5^{\circ}$ $2 \theta$ (Moore and Reynolds 1997). 
Vitrinite derives from the thermal degradation of lignin and cellulose, and can be found in kerogens rich in high plant fragments and in coals (Stach et al. 1982). As the maturity increases, a progressive ordering takes place in the vitrinite molecular structure, which determines an increasing reflection capacity of incident light. Vitrinite reflectance strictly depends on the thermal evolution of the hosting sediments and is correlated to the stages of hydrocarbon generation, coal rank, and other thermal parameters in sedimentary environments (Durand 1980). Vitrinite reflectance becomes anisotropic from maturity levels in the oil window (about $1 \%$ ) and increases with increasing maturity. Thus, in organic diagenesis and catagenesis, random reflectance $\left(R_{\mathrm{o}} \%\right)$ is generally used, whereas from metagenesis onward, $R_{\max }$ is generally preferred to describe levels of coalification. Specimens for vitrinite reflectance were prepared according to standardized procedures described in Bustin et al. (1990). Picked kerogen particles were cold set into epoxy resin blocks and polished using carborundum papers and isopropanol as lubricant. After washing the sample in order to remove debris, three alumina powders of decreasing grain size $(1,0.3,0.01 \mu \mathrm{m})$ were used to polish the samples. Random reflectance was measured under oil immersion $\left(\mathrm{n}_{\mathrm{e}} 1.518\right.$, at $\left.23^{\circ} \mathrm{C}\right)$, with a Zeiss Axioskop $40 \mathrm{~A}$ pol microscope-photometer system and calibrated against standards of certified reflectance. On each sample, measurements were taken on vitrinite or bitumen unaltered fragments. Mean vitrinite $\left(R_{\mathrm{o}} \%\right)$ and bitumen $\left(R_{\mathrm{b}} \%\right)$ reflectance values were calculated from the arithmetic mean of these measurements. $R_{\mathrm{b}}$ values have been converted into vitrinite reflectance equivalent values $\left(R_{\text {oeq }} \%\right)$ according to Jacob and Hiltmann (1985).

\section{Magnetic techniques: RT-AMS, LT-AMS, AARM, and paleomagnetism}

Sampling for AMS and paleomagnetic analyses was done with a gas-powered drill machine in hard rocks and an electric drill in marls, shales, fault gouge, and microbreccia. Most sites are located in fault rocks whose protoliths are Cenozoic rocks belonging to the footwall of the main thrust since rocks in the hanging wall (mainly marine Jurassic limestones) do not show internal deformation at the outcrop scale. Samples were collected from 23 sites distributed in the three sampled areas: 13 sites at the Matute area (named as FCA in Table 3), 7 sites at the Panzares area (PA in Table 3), and 3 sites at the Préjano area (PRE in Table 3). A total of 395 standard specimens $(2.5 \mathrm{~cm}$ in diameter, $2.1 \mathrm{~cm}$ in height) were obtained from the three sampled areas.

The specimens were measured for their AMS at room temperature (RT-AMS) with a KLY-3S susceptibility meter (AGICO, Czech Republic), a bridge at low magnetic field
(300 A/m, $875 \mathrm{~Hz}$ ) at the University of Zaragoza. These measurements provide the orientations and magnitudes of the $k_{\min } \geq k_{\text {int }} \geq k_{\max }$ axes of the AMS ellipsoid, hence help to define the fabric that is characterized by the magnetic lineation $\left(k_{\max }\right)$ and the magnetic foliation (plane perpendicular to $k_{\min }$ ). Relationship between these axes (normalized by means of Jelinek's method 1977, Table 1) provides (Jelinek 1981) (1) the corrected anisotropy degree, $P^{\prime}$, giving the intensity of the preferred orientation of minerals, and (2) the shape parameter, T, which varies between $T=-1$ (prolate ellipsoids) and $T=+1$ (oblate ellipsoids):

$$
\begin{aligned}
P^{\prime} & =\exp \sqrt{2\left[\left(\mu_{1}-\mu_{m}\right)^{2}+\left(\mu_{2}-\mu_{m}\right)^{2}+\left(\mu_{3}-\mu_{m}\right)^{2}\right]}, \\
T & =\frac{2 \mu_{2}-\mu_{1}-\mu_{3}}{\mu_{1}-\mu_{3}},
\end{aligned}
$$

where $\mu_{1}, \mu_{2}$, and $\mu_{3}$ represent $\ln \left(k_{\max }\right), \ln \left(k_{\text {int }}\right)$, and $\ln \left(k_{\min }\right)$, respectively, and $\mu_{\mathrm{m}}=\left(\mu_{1}+\mu_{2}+\mu_{3}\right) / 3$. The average directional and scalar value for each site was calculated using Jelinek (1978) statistics with Anisoft 4.2 (Chadima and Jelinek 2009).

In order to characterize the mineralogy of the susceptibility carriers, temperature-dependent magnetic susceptibility $(k-\mathrm{T})$ curves were performed from $\approx 50 \mathrm{mg}$ rock powders coming from 9 specimens covering the whole range of susceptibility values. A decreasing hyperbolic shape of the initial part of the heating curves is typical for paramagnetic minerals while a straight and slight positive slope indicates the presence of ferromagnetic phases (Hrouda et al. 1997). The presence of ferromagnetic phases is also marked by a sharp decrease in susceptibility at high temperature due to the Curie or Néel transition from ferromagnetic to paramagnetic behavior. In this study, the peak method and the $1 / k$ method (Lattard et al. 2006; Petrovsky and Kapicka 2006) were used to determine the Curie or Néel temperatures. In addition, cooling runs are used to check the reversibility of the heating curves and therefore the stability of the magnetic phases. These experiments are performed using the KLY-3 kappabridge combined with a CS-3 furnace (temperature range between 40 and $700{ }^{\circ} \mathrm{C}$, AGICO), according to heating rates around $13 \%$ min, under argon atmosphere in order to reduce mineral oxidations. The raw data, corrected for the empty furnace, were processed using Cureval 8.0 software (Chadima and Hrouda 2009).

AMS at low temperature (LT-AMS) was also used to elucidate the respective contributions of both principal magnetic carriers (ferromagnetic s.l. and paramagnetic) of the magnetic fabric, by means of both the magnetic susceptibility value and the orientation of the three magnetic axes. Low temperatures enhance the magnetic susceptibility of paramagnetic minerals, as established by the Curie-Weiss law $(k=C / T-T c)$, where $k$ is the paramagnetic susceptibility, $\mathrm{C}$ is the Curie constant, $\mathrm{T}$ is the absolute temperature, 


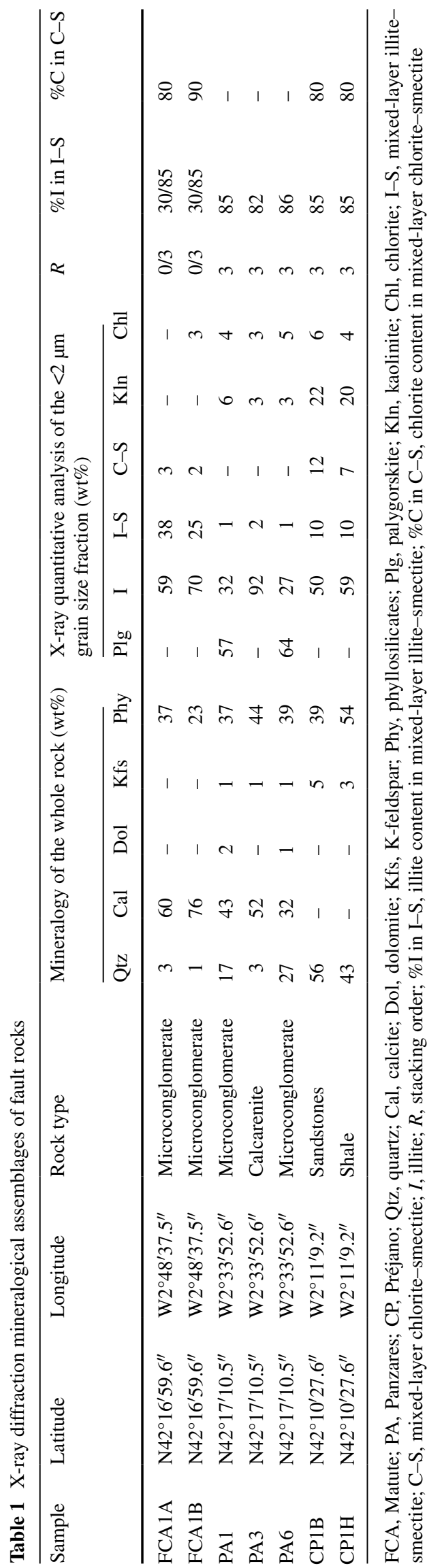

and $T c$ is the Curie temperature (Ritcher and van der Pluijm 1994; Dunlop and Özdemir 1997; Parés and Van der Pluijm 2002). Assuming an ideal paramagnetic phase with a paramagnetic Curie temperature $(T c)$ around $0 \mathrm{~K}$, its expected magnetic susceptibility at low temperature $(77 \mathrm{~K})$ would be approximately 3.8 times higher than at room temperature (i.e., the ratio of temperatures, 292/77, Ritcher and van der Pluijm 1994; Lüneburg et al. 1999). The presence of ferromagnetic $s . l$. minerals (which have $T c$ different than $0 \mathrm{~K}$ ) decreases this ratio (Oliva-Urcia et al. 2010a). The LTAMS measurements were taken on 40 standard specimens from 7 sites, with the same apparatus and software used at room temperature. The sites were selected depending on their bulk susceptibility value, the orientation of $k_{\max }$, and the scattering of the axes of the magnetic ellipsoid at room temperature. The analyzed specimens were immersed for 30-40 min in a Dewar filled with liquid nitrogen before measurement (in order to acquire a homogeneous temperature of $-195^{\circ} \mathrm{C} / 77 \mathrm{~K}$ ), and again for 10 more min between each of the three spinner positions required by the measurement procedure. This technique gives reproducible results (Hirt and Gehring 1991; Lüneburg et al. 1999; Oliva-Urcia et al. 2010a, b).

When the magnetic fabric results from the contribution of ferro- and paramagnetic phases, AARM (anisotropy of the anhysteretic remanent magnetization) is useful to separate the ferromagnetic s.l. subfabric (Martín-Hernández and Ferré 2007). In our case, AARM was applied to three sites with 5-7 specimens per site representative of the three studied areas. It was applied using the AF system of the 2G-cryogenic magnetometer at the University of Burgos. Specimens were subjected to an AF demagnetizing peak field of $90 \mathrm{mT}$ while a $0.05 \mathrm{mT}$ direct field was applied. This procedure was performed in nine different axes for every specimen, measuring the remanent magnetization for every position in the 2G-cryogenic magnetometer. After each measurement, the specimen was demagnetized along three orthogonal directions with an AF peak field of $100 \mathrm{mT}$. The computation of the AARM ellipsoid, which enables identification of the low coercivity ferrimagnetic subfabric, is done using the University of Burgos' modified version of the MS Excel provided by the Institute for Rock Magnetism, University of Minneapolis. Averages for each site were performed with Stereonet 9.2.0 (Allmendinger et al. 2013; Cardozo and Allmendinger 2013).

Since processes linked to thrusting are liable to produce remagnetizations, paleomagnetic analyses in fault rocks can a priori give clues about (1) the age of remagnetization (by means of the paleomagnetic direction resulting from the acquisition of remagnetization), (2) the intensity of deformation (since ferromagnetic particles can be reoriented by internal deformation of the whole-rock volume after magnetization acquisition, see, e.g., Kligfield et al. 
1983; Cogné and Perroud 1985; Lowrie et al. 1986; Borradaile 1997; Oliva-Urcia et al. 2010c), and (3) other processes underwent by fault zones such as horizontal- or vertical-axes rotations (by means of deviations of the paleomagnetic vector, especially azimuth, with respect to reasonable directions). Furthermore, paleomagnetism also allows to obtain information about the magnetic mineralogy and probable magnetic carriers of the AMS. In order to acquire paleomagnetic data, 86 specimens from 11 different sites (7-8 specimens per site) in the three studied areas were chosen to be thermally demagnetized from room temperature to $685{ }^{\circ} \mathrm{C}$ at temperature steps between 50 and $10{ }^{\circ} \mathrm{C}$. A TD48 ASC furnace and a $2 \mathrm{G}$ cryogenic magnetometer at the paleomagnetic laboratory of the University of Burgos were used to stepwise demagnetize the specimens and to measure their remanence, respectively. Lithology of specimens is variable and corresponds mainly to brecciated conglomerates with reddish matrix, and grayish siltstones and limestones. Characteristic components following the principal component analyses (PCA, Kirschvink 1980) and demagnetization circles (Bailey and Halls 1978) were calculated using Remasoft 3.0 software (Chadima and Hrouda 2006). When possible, site averages were obtained using Fisher (1953) statistics by means of Stereonet 9.2.0 (Allmendinger et al. 2013; Cardozo and Allmendinger 2013).

\section{Results}

\section{Structural features. Kinematic indicators}

In the Matute area, the Cameros-Demanda thrust shows a slice of Mesozoic rocks (Upper Triassic to Lower Cretaceous) between the Paleozoic ones in the hanging wall and the shallow-dipping Cenozoic deposits of the Ebro Basin that show a footwall ramp geometry (Fig. 2 cross section of Matute sector). Overturned beds (younging northward), within this horse, show at least two hectometric-scale folds, defining an antiformal syncline and a synformal anticline. Mean fold axis is parallel (or slightly oblique) to the dip direction of the thrust surfaces (Fig. 3b), indicating folding consistent with dextral-reverse shear between the two NW-SE-striking thrust surfaces (Cortés Gracia and CasasSainz 1997). Syn-tectonic sedimentary deposits cut by the thrust correspond to R3 and R4 units of Muñoz-Jiménez and Casas-Sainz (1997), Oligocene-Miocene in age, that allow to assign a minimum displacement of $2000 \mathrm{~m}$ and probable maximum depths of $500 \mathrm{~m}$ for thrusting in these rocks (Fig. 2 cross section of Matute sector).

At the contact with the lower thrust surface, overturned beds of Jurassic limestones in the hanging wall become parallel to the main thrust (Fig. 3b, c). In the footwall, the Cenozoic conglomerates show up to three secondary,
Fig. 3 Photographs showing the studied sites at the Matute sector. a Cameros-Demanda thrust at Matute; overall view showing the north-verging folds of Jurassic limestones in the hanging wall and the horizontal Cenozoic sequence in the footwall. b Close-up view of the Cameros-Demanda thrust in the same site, showing three minor thrust surfaces in the Cenozoic brecciated conglomerates of the footwall and stereoplots of structural data at the same sector (lower hemisphere equal area projection). Stereoplot is done with R.W. Allmendinger's Stereonet program (Allmendinger et al. 2013; Cardozo and Allmendinger 2013). c Calcareous breccia just below the main thrust surface

synthetic, shallow-dipping fault surfaces, with a spacing of several meters (Fig. 3b). Between these faults, conglomerates are strongly deformed showing pressure solution cleavage associated with S/C structures. Strike of cleavage planes ranges between E-W and NW-SE with an average WNW-ESE, dipping $60^{\circ} \mathrm{S}$ (Fig. 3b). Orientations of $\mathrm{C}$ and thrust planes are more irregular and generally show shallower dips. Intersection lineations between $\mathrm{S}$ and $\mathrm{C}$ planes show a mean plunge of $20^{\circ} \mathrm{W}$. Striations on fault surfaces show a maximum about 170 and are sub-horizontal, more or less perpendicular to the intersection lineation between $\mathrm{S}$ and $\mathrm{C}$ planes (Fig. 3b).

At the microscopic scale, pressure solution cleavage can be clearly distinguished, having different degrees of development according to the distance to the main thrust (Fig. 6a-c). Cleavage surfaces are clearly developed in the sandy to clayey matrix, concentrate on opaque minerals (probably $\mathrm{Fe}$ oxides), and show a sigmoidal shape at the intersection with $\mathrm{C}$ planes and surrounding the limestone clasts.

In the Panzares area, the marine Jurassic limestones belonging to the hanging wall of the Cameros thrust are preserved in three klippen overlying the horizontal Cenozoic conglomerates of unit R3 (Upper Oligocene, MuñozJiménez and Casas-Sainz 1997; Figs. 2, 4a-c) with flats in both walls. The main thrust surface is practically horizontal (Fig. 4b-d), and secondary thrusts affecting the hanging wall show dips up to $30^{\circ}$ toward the SW and NE (Fig. 4b, e). According to our cross section (Fig. 2 cross section of Panzares sector), the minimum horizontal displacement is about $0.5 \mathrm{~km}$, and the maximum depth for the development of structures is about $600 \mathrm{~m}$. S/C structures develop in a clayey level located at the thrust surface (Fig. 4c): Slaty cleavage planes show NE-SW to E-W strike and intermediate dips to the South; shear planes are sub-horizontal or show shallow dips and highly variable intersection lineations (Fig. 4c PA1). Several generations of C planes can be observed in thin section, some of them consisting of net surfaces concentrating phyllosilicates and probable $\mathrm{Fe}$ oxides and the younger ones involving thicker bands and cataclasis along the shear surfaces (Fig. 6e). The geometrical arrangement of different generations of $\mathrm{C}$ planes indicates that the dominant shear direction probably changed 


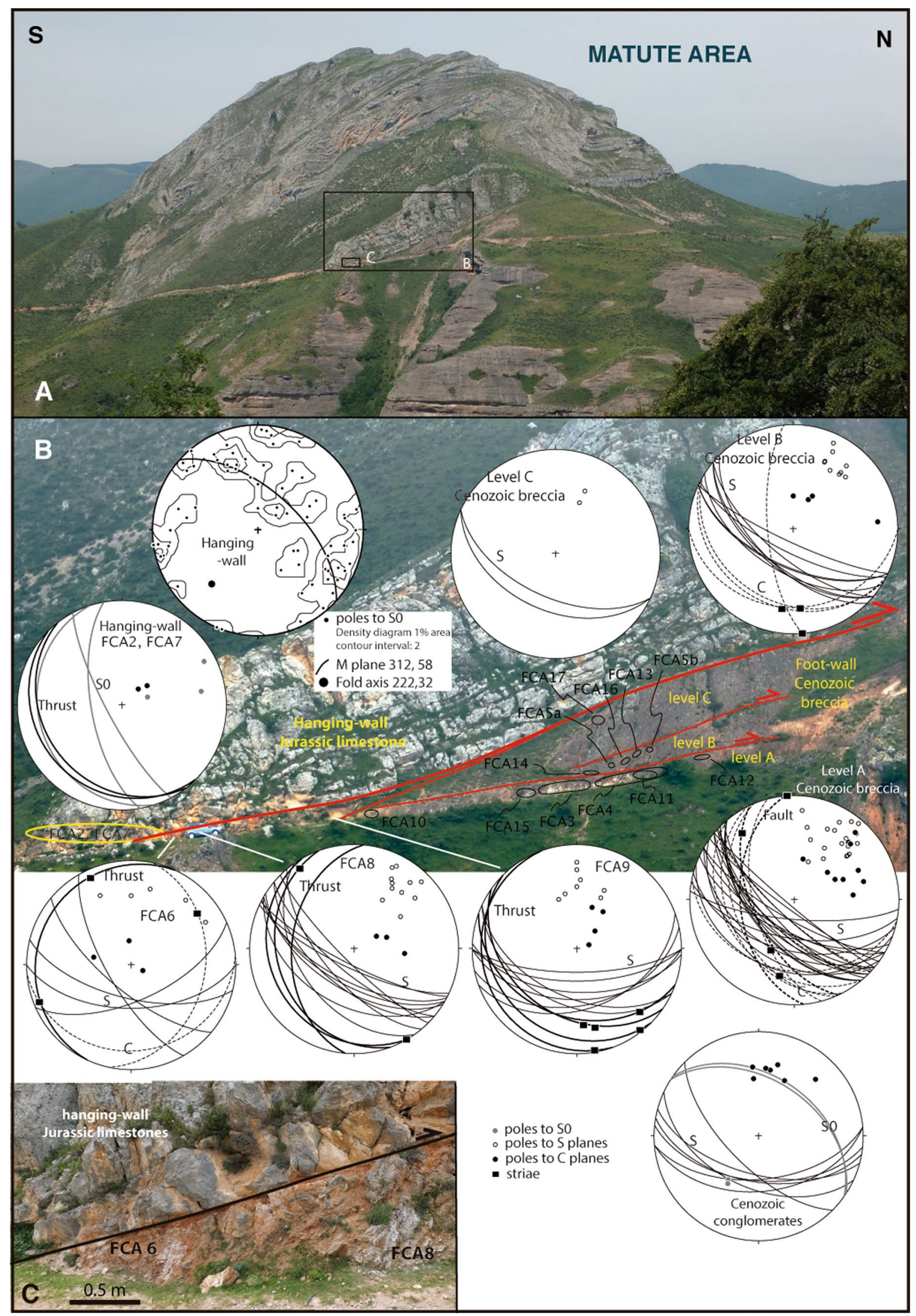




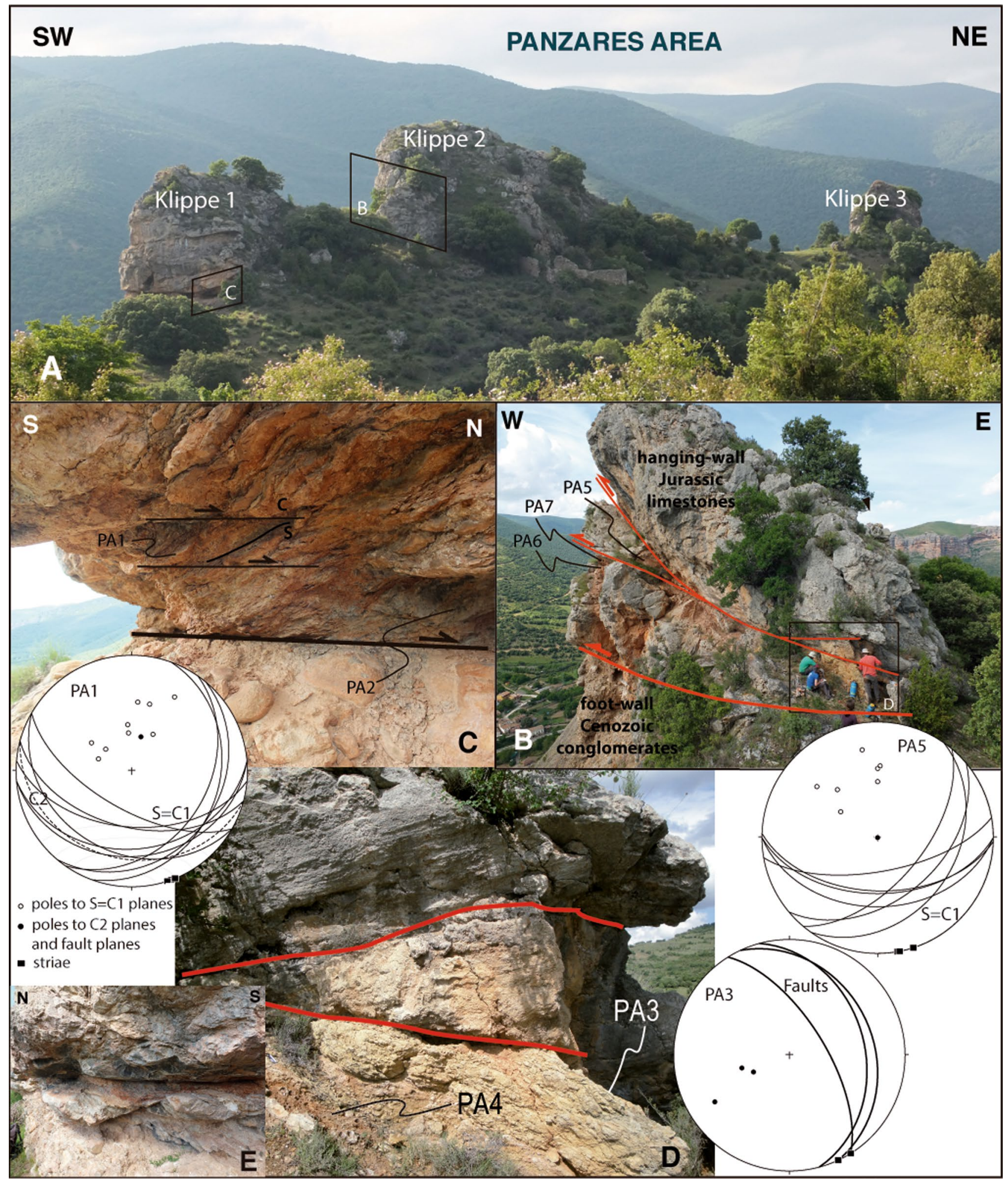

Fig. 4 Photographs showing the studied sites at the Panzares sector. a Cameros-Demanda thrust in the Panzares area; overall view showing three klippen. b Close-up view of the Cameros-Demanda thrust in the same site, showing the second klippe of Lower Jurassic limestones. c S/C structures in the fault zone of the first klippe. d, e Close-up view of the thrust plane in the second klippe. Stereoplot of structural data at the same sector (lower hemisphere, equal area projection). Stereoplot is done with R.W. Allmendinger's Stereonet program (Allmendinger et al. 2013; Cardozo and Allmendinger 2013) 
its plunge during the deformation process, from steeply plunging to the $\mathrm{SE}$ (corresponding to $\mathrm{C} 1$ planes in Fig. 6e) to shallowly plunging in the same direction (corresponding to $\mathrm{C} 2$ planes in Fig. 6e). During this second stage, $\mathrm{C} 1$ surfaces were probably re-activated as foliation planes (identified in outcrop as S surfaces), thus preserving their original structure within the microlithons. Within the conglomerates, pressure solution structures and shear bands are also present (Fig. 6f). In outcrop and thin section, S/C structures and striae on $\mathrm{C}$ planes are consistent with an average movement of the hanging wall toward the NNW (Fig. 4c).

In the Préjano area, the outcropping thrust surface corresponds to the inverted Mesozoic fault bounding the Cameros basin toward the north. During the Cenozoic inversion, a shortcut formed in its footwall and the total shortening is distributed between two thrusts (Muñoz-Jiménez and Casas-Sainz 1997): a blind lower thrust with a horizontal displacement of about $15 \mathrm{~km}$, and an upper thrust (cropping out in the Préjano area) with a minimum displacement of $2 \mathrm{~km}$ and a hanging wall flat-footwall ramp geometry (Fig. 5a). In the hanging wall, a complete marine Jurassic series crops out, and in the footwall an overturned sequence of Albian sandstones and coal measures (Fig. 5a, b), overlain by Cenozoic conglomerates, and sandstones (units R2 and R5, separated by an unconformity) can be seen (Fig. 2 cross section of Préjano sector). Thrusting involves the coal-bearing Albian deposits, having shear zones and slickenside striations (Fig. 5c, d). Fault rocks are marls and sandstones located in the footwall of the thrust. Thinsection observations indicate gouge and microbreccia with clear foliation, which is defined by changes in color probably related to different coal content, and incipient, relatively short $\mathrm{C}$ surfaces that cannot be distinguished at the outcrop scale (Fig. 6d). The transport direction of the thrust can be estimated from the (highly variable) slickenside striations on the fault plane (Fig. 5d) and the fold axis obtained from the normal (hanging wall) and overturned (footwall) beds. Both markers point to a NE-directed movement of the hanging wall.

\section{Paleothermal results: mixed-layer I-S analyses}

X-ray diffraction analyses of whole-rock samples and $<2 \mu \mathrm{m}$ grain size fraction are shown in Table 1 . Samples are from S/C structures in Cenozoic conglomerates near the fault surface in the Matute (FCA samples) or in Panzares (PA samples) area and from Albian sandstones and shales at the footwall of the thrust in the Préjano area (note that samples from this area are noted as CP in Table 1).

In the Matute area, fault rocks are mainly composed of calcite (mean $68 \%$ ), phyllosilicates (30\%), and minor amounts of quartz $(2 \%)$. In the $<2 \mu \mathrm{m}$ grain size fraction, among the phyllosilicates group, illite and mixed-layer illite-smectite are the major minerals with subordinate amounts of mixed-layer chlorite-smectite (C-S). Mixedlayer I-S corresponds to long range ordered $\mathrm{I}-\mathrm{S}$ with an illite content of $85 \%$ and high expandable I-S with an illite content of $30 \%$ (Fig. 7a). The coexistence of two populations of mixed-layer I-S together with the presence of mixed-layer $\mathrm{C}-\mathrm{S}$ suggests the superposition of reactions typical of low grade on preexisting higher-grade mineral assemblages. These retrograde reactions have been well documented in a variety of geological settings as fluidmediated processes occurring under diagenetic conditions (Nieto et al. 2005).

In the Panzares area, Cenozoic conglomerates are mainly characterized by calcite, phyllosilicates, and quartz, whereas dolomite and $\mathrm{k}$-feldspar occur as minor phases ( $<2 \%$; Table 1$)$. X-ray patterns of the $<2 \mu \mathrm{m}$ grain size fraction show an illite- or palygorskite-rich composition and small amounts of kaolinite (mean $4 \%$ ), chlorite (4\%), and mixed-layer I-S (1\%; Fig. 7b). Palygorskite forms as a result of the interaction along faults of $\mathrm{Si}$ - and $\mathrm{Mg}$-rich alkali oxidized fluids with fragmental minerals such as chlorite at temperatures between 50 and $150{ }^{\circ} \mathrm{C}$ (Haines and Van der Pluijm 2012) or generally $<200{ }^{\circ} \mathrm{C}$ (Jones and Galan 1988). Mixed-layer I-S displays R3 stacking order and an illite content between 82 and $86 \%$, indicating deep diagenetic conditions.

In the Préjano area, both shales and sandstones at the footwall of the thrust show a mineralogical composition made of quartz, phyllosilicates, and k-feldspar. The $<2 \mu \mathrm{m}$ grain size fraction is mostly characterized by an illite-rich composition (50-59\%) and subordinate amounts of kaolinite (20-22\%), mixed-layer I-S (10 \%) and C-S (7-12\%), and chlorite (4-6 \%; Table 1; Fig. 7c). Temperaturedependent clay minerals are R3 mixed-layer I-S with an illite content of $85 \%$, indicating deep diagenetic conditions and shallow burial depths.

\section{Paleothermal results: vitrinite reflectance analyses}

Results of optical analyses on organic matter dispersed in sediments are summarized in Table 2. In the Préjano area, samples were collected at the thrust footwall, mainly from sandstone layers. Charcoal preserved in thin laminas (CP1A) and organic fragments dispersed in silty and clayey beds $(\mathrm{CP} 1 \mathrm{Ca})$ were collected a few meters from the thrust surface, whereas bitumen $(\mathrm{CP} 1 \mathrm{E}, \mathrm{CP} 1 \mathrm{~F})$ was sampled closer to it (Figs. 2, 8).

Microscopic analyses highlight that samples are characterized by abundant, well-preserved organic fragments. Sample CP1C shows fragments belonging to the huminite-vitrinite group and subordinately to the fusinite group. Moreover, pyrite is locally present, either finely 


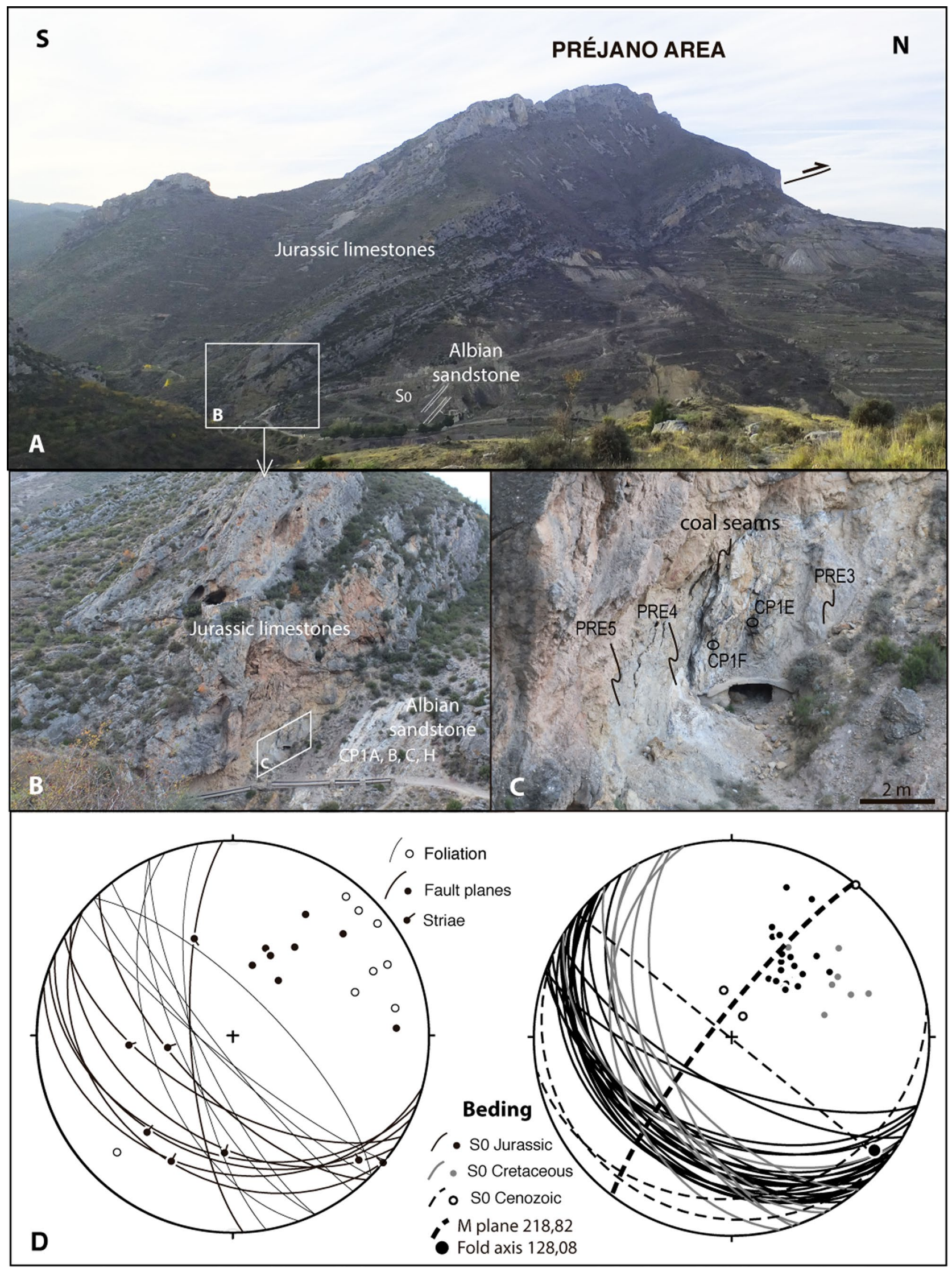


4Fig. 5 Photographs showing the studied sites at the Préjano sector. a Cameros-Demanda thrust in the Préjano area, showing the Jurassic limestones in the hanging wall and the Albian sandstones and shales in the footwall. b, c Close-up view of the thrust in the same area showing the location of sites and deformed coal seams in the proximity of the thrust surface. d Stereoplot of structural data at the same sector (lower hemisphere equal area projection). Stereoplot is done with R. W. Allmendinger's Stereonet program (Allmendinger et al. 2013; Cardozo and Allmendinger 2013)

dispersed or in small globular aggregates, associated with both groups of macerals. Histogram for CP1A coal sample is characterized by unimodal distribution with a mean value of $0.52 \pm 0.07$ (Fig. 8a). Sample CP1Ca shows a bimodal distribution: vitrinite group macerals with mean values of $0.50 \pm 0.04$, and fusinite macerals and reworked materials whose mean reflectance was not taken into account (Fig. 8b). Bitumen samples (CP1E, CP1F) suggest a unimodal distribution of reflectance with mean values of $0.52 \pm 0.11$ and $0.54 \pm 0.10$, respectively (Fig. 8c), corresponding to equivalent reflectance values of 0.72 and 0.73 using Jacob and Hiltmann's equation (1985). These values of reflectance indicate temperatures of about 83-84 and $109-110^{\circ} \mathrm{C}$, respectively.

Reflectance data indicate diagenetic conditions in the footwall of the Cameros thrust. Furthermore, a slight increase in thermal maturity moving toward the fault surface is detected from the early mature stage (about $0.5 \%$ on coal and dispersed organic matter) to the mature stage of hydrocarbon generation (about $0.7 \%$ on bitumen).

\section{Magnetic methods: magnetic mineralogy}

The sampled rocks show a large range of bulk magnetic susceptibility values, from negative (8 out of 395 specimens, in the Matute and Panzares sectors) to very high values in the Matute sector, reaching $11788 \times 10^{-6} \mathrm{SI}$ (specimen FCA15-9b, Fig. 9). At the Panzares and Préjano sectors, all specimens show bulk magnetic susceptibility values lower than 80 and $180 \times 10^{-6} \mathrm{SI}$, respectively (Fig. 9). At the Matute sector, the high values of susceptibility are present in the three levels of fault breccia developed in the Cenozoic conglomerates (Table 3 ).

Thermomagnetic $(k-\mathrm{T})$ curves can be grouped into two types: (1) In the 6 measured specimens having low magnetic susceptibility values $\left(\mathrm{Km}<100 \times 10^{-6}\right.$ SI, Fig. 10a, b), $k-\mathrm{T}$ curves show a decreasing heating curve beginning with a hyperbolic shape, indicating that the paramagnetic fraction (probably due to phyllosilicates) controls the susceptibility at room temperature. These curves show an abrupt increase in susceptibility from $450-550{ }^{\circ} \mathrm{C}$ and then a sudden drop. The conspicuous increase in susceptibility of the cooling curve in this temperature interval points to the neoformation of magnetite at high temperatures. (2) In the 3 specimens having high values (Fig. 10c), $k$-T curves beginning by a slight positive slope are typical for the presence of ferromagnetic phases. This is also evidenced by sharp decreases in susceptibility at the Curie or Néel temperature characteristic of each mineral. Curves FCA178, FCA12-3a, and FCA5-2 (Fig. 10c) show a progressive decrease in susceptibility above $325{ }^{\circ} \mathrm{C}$. The increase observed above $500{ }^{\circ} \mathrm{C}$ is probably a Hopkinson peak, in the vicinity of the Curie temperature of magnetite at $580{ }^{\circ} \mathrm{C}$. A final decay of susceptibility at $680{ }^{\circ} \mathrm{C}$ points to the Néel temperature of hematite. These data suggest that magnetite and to a lesser degree hematite are the main ferromagnetic minerals in the Matute sector, in samples having high magnetic susceptibility (Fig. 10c).

\section{AMS results: directional features of RT-AMS}

As a whole, the magnetic foliation is better clustered than the magnetic lineation, consistently with the predominance of oblate ellipsoids (Fig. 11a, b). In the Matute area, the maximum of magnetic foliation $(005,32)$ indicates a main WNW-ESE strike with steep dips. The maximum of magnetic lineation is well defined $(140,48)$, in spite of scattering of data, because of the high amount of collected specimens. In a closer look, magnetic fabrics vary depending on the location of the sites with respect to the thrust surface, relatively constant in the deformed Cenozoic conglomerates of the footwall, with intermediate-plunging, SE-oriented magnetic lineation and $k_{\min }$ axes oblique to the thrust plane (sites FCA3 to FCA5 and FCA10 to FCA17, Fig. 12a; Table 4), and more variable in the calcareous breccia of the shear zone just below the main thrust surface. Here, magnetic lineation shows shallow plunges and varies in orientation from NE-SW to N-S and E-W (sites FCA6, FCA8, and FCA9, respectively, Fig. 12a; Table 4). This variability also involves the magnetic foliation that changes between sites from NE-SW to NW-SE strikes. Results of magnetic fabrics in the Jurassic limestones of the hanging wall are poor, with high scattering (sites FCA2 and FCA7, Fig. 12a), although relatively consistent with the directions obtained in the footwall.

In the Panzares area, the magnetic foliation shows E-W to NE-SW strikes and variable dips. Variability in the strike of magnetic foliation is partly due to its shallow dips. Shallow plunging magnetic lineations dominate (except in site PA5, Fig. 12b) varying from the strike to the dip directions of the magnetic foliation. Magnetic lineation trends E-W in sites PA1 and PA6; NE-SW in sites PA4 and PA7; and $\mathrm{N}-\mathrm{S}$ in sites PA2, PA3, and PA5 (Fig. 12b; Table 4). In general, it is distributed along a girdle shallowly dipping to the South. 


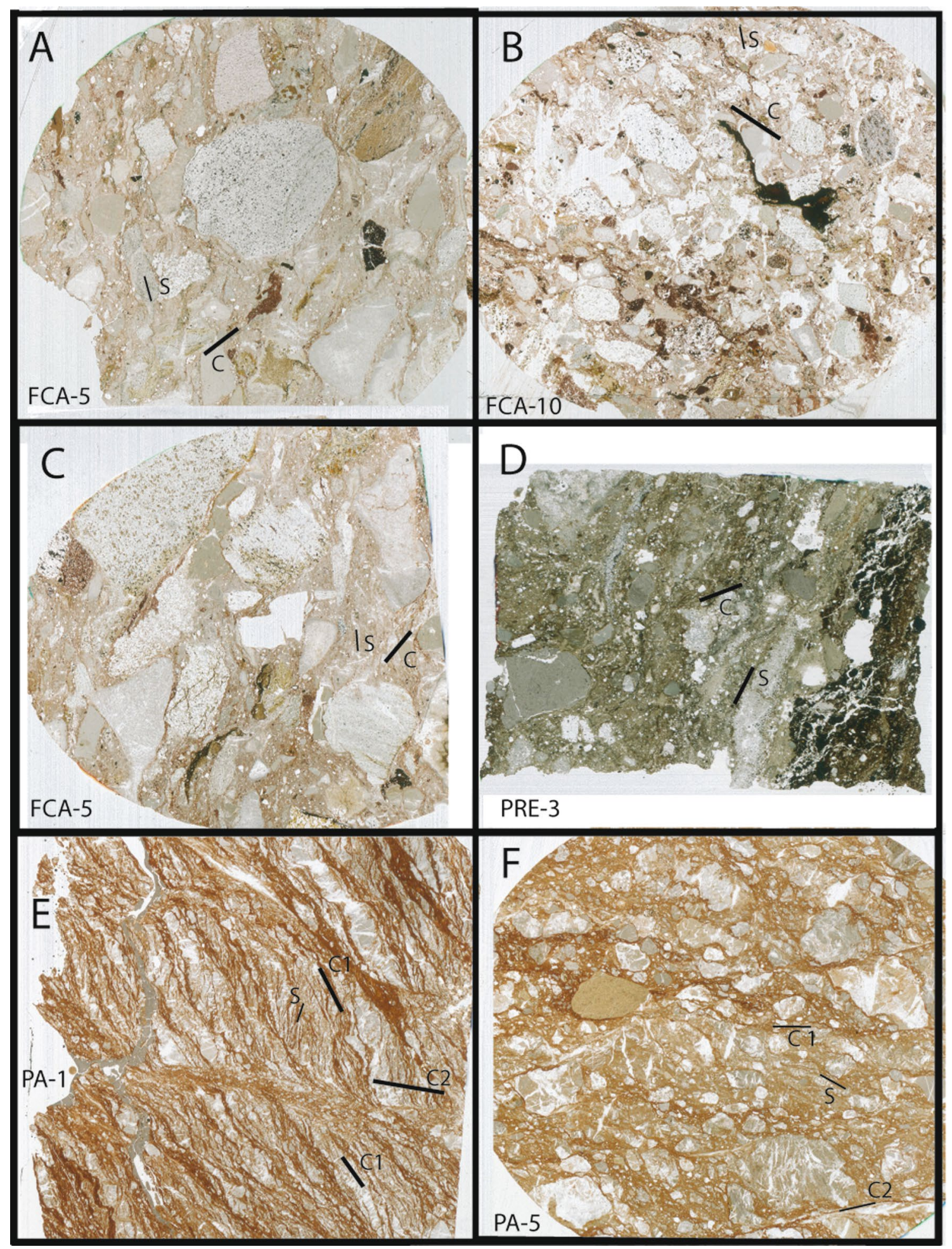

Fig. 6 Photographs of thin sections representative of the fault rocks in the three studied areas showing different aspects of the S/C structures. A-c are referring to the Matute area. d Préjano area. e, f Panzares area. Width of photographs $2 \mathrm{~cm}$

Finally, in the Préjano area, where a lower number of specimens were analyzed, a NW-SE strike with very variable dips dominates for the tectonic foliation (Figs. 11b, 12c) and an average sub-horizontal plunge and NW-SE trend for the better grouped magnetic lineation (Figs. 11b, $12 \mathrm{c})$. 

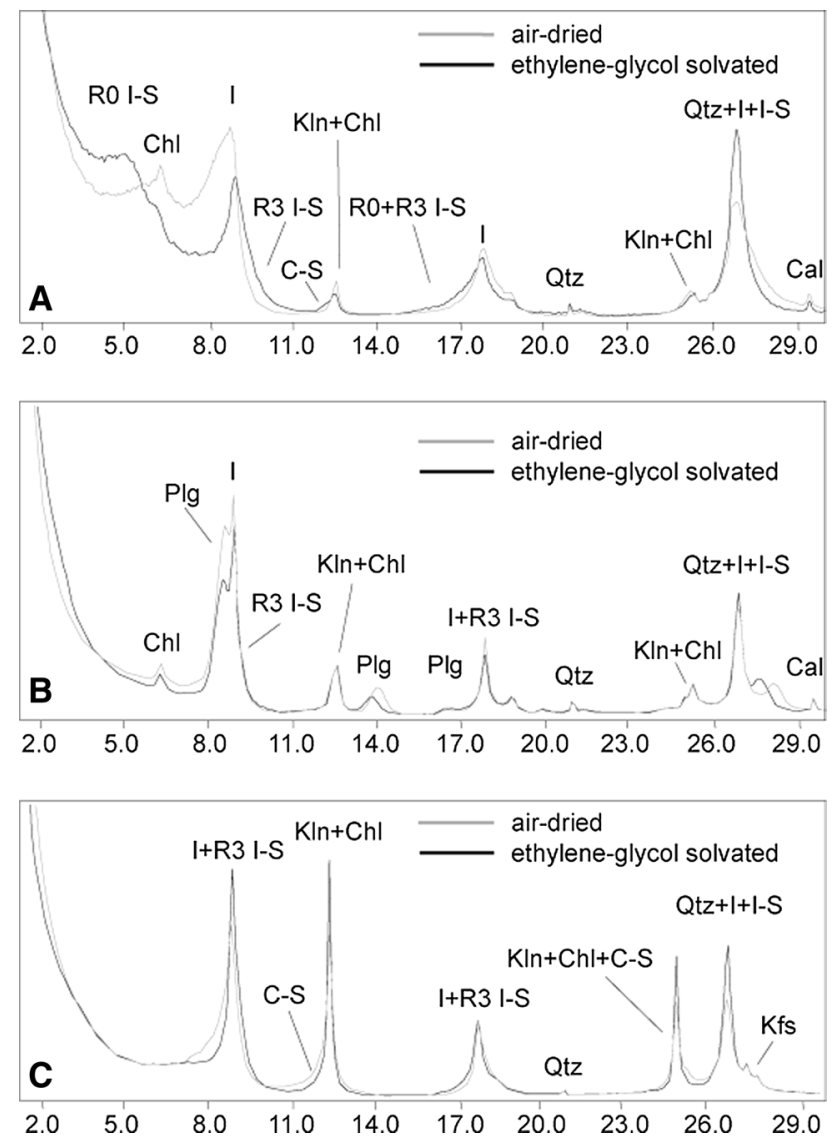

Fig. 7 Selected X-ray diffraction patterns of the $<2 \mu \mathrm{m}$ grain size fraction: a sample FCA1B in the Matute area, b sample PA6 in the Panzares area; $\mathbf{c}$ sample $\mathrm{CP} 1 \mathrm{H}$ in the Préjano area

\section{LT-AMS and AARM}

AMS measurements at low temperature indicate that the bulk susceptibility does not increase in specimens having high bulk susceptibility values at room temperature (sites FCA15, FCA5, Table 5; Fig. 13), confirming that ferromagnetic phases are the dominant magnetic carriers. For the other sites, the increase in susceptibility at low temperature with respect to room temperature corresponds to a factor between 1.25 and 2.84 (Table 5). Such ratios lower than 3.8 and above 1 may be related to either a partial contribution of ferromagnetic phases to the susceptibility or to a paramagnetic phase with a paramagnetic Curie temperature above $0 \mathrm{~K}$ (chlorite and micas can have $T c$ around 30-35 K). Despite the lower increase in the bulk susceptibility at low temperature, the magnetic axes of all measured sites remain rather unchanged in orientation at low and room temperatures (Fig. 13; Table 5) except for FCA8.

The test of AARM in representative sites of the three studied areas (FCA15, PA1, and PRE5) indicates that the contribution of the ferromagnetic fabric shows orientations and position of axes similar to the RT-AMS in the Matute and Panzares sites, although no clear pattern can be defined in PRE5 (Préjano site), where results are strongly scattered at the specimen level (Fig. 13).

\section{Paleomagnetic results}

The intensity of the natural remanent magnetization (NRM) is low in Préjano and Panzares areas (between 0.1 and $1 \times 10 \mathrm{~mA} / \mathrm{m})$ and higher in Matute outcrops $(0.5-20$ $\mathrm{A} / \mathrm{m})$. A strong heterogeneity is observed for both the magnetic properties and directions of components (between and within sites). Nevertheless, four components have been distinguished in the different sites and specimens considering their unblocking temperature spectrum: low unblocking temperature component (named LT) between 150 and $350{ }^{\circ} \mathrm{C}$; intermediate unblocking temperature (IT) between 350 and $580{ }^{\circ} \mathrm{C}$, probably carried by magnetite; and a hightemperature component (HT) with maximum unblocking temperatures higher than $600{ }^{\circ} \mathrm{C}$, probably carried by hematite. In addition, a systematic sharp drop observed at temperatures below $150{ }^{\circ} \mathrm{C}$ is observed (examples in Fig. 14a, b). This component (named G) is probably due to goethite. Figure 14 shows different examples of thermal demagnetization of representative samples in which two or three of the described components can be identified.

Tectonic correction was not applied in most sites because bedding is not recognizable within fault rocks, and no consistent directions or polarities were obtained considering the bedding attitude of the footwall units, either (N135E, $30 \mathrm{NE}$ for the Matute sites, $6^{\circ}-10^{\circ}$ to the $\mathrm{NW}$ in the Panzares sites and SW-dipping overturned beds in the

Table 2 Organic matter and bitumen maturity in the Préjano area

\begin{tabular}{|c|c|c|c|c|c|c|c|c|c|c|}
\hline Sample & Latitude & Longitude & Lithology & Type & $R_{\mathrm{o}} \%$ & St. dev & $R_{\mathrm{bit}} \%$ & St. dev & $R_{\mathrm{eq}} \%$ & Counts \\
\hline CP1A & $\mathrm{N} 42^{\circ} 10^{\prime} 27.6^{\prime \prime}$ & $\mathrm{W} 42^{\circ} 11^{\prime} 9.2^{\prime \prime}$ & Sandstone & Coal & 0.52 & 0.07 & & & & 57 \\
\hline $\mathrm{CP} 1 \mathrm{C}$ & $\mathrm{N} 42^{\circ} 10^{\prime} 27.6^{\prime \prime}$ & $\mathrm{W} 42^{\circ} 11^{\prime} 9.2^{\prime \prime}$ & Sandstone & DOM & 0.50 & 0.04 & & & & 92 \\
\hline CP1E & $\mathrm{N} 42^{\circ} 10^{\prime} 27.6^{\prime \prime}$ & $\mathrm{W} 42^{\circ} 11^{\prime} 9.2^{\prime \prime}$ & Sandstone & Bitumen & & & 0.52 & 0.11 & 0.72 & 130 \\
\hline $\mathrm{CP} 1 \mathrm{~F}$ & $\mathrm{~N} 42^{\circ} 10^{\prime} 27.6^{\prime \prime}$ & $\mathrm{W} 42^{\circ} 11^{\prime} 9.2^{\prime \prime}$ & Sandstone & Bitumen & & & 0.54 & 0.10 & 0.73 & 161 \\
\hline
\end{tabular}

CP, Préjano; DOM, dispersed organic matter; $R_{\mathrm{o}} \%$, vitrinite reflectance; $R_{\mathrm{bit}} \%$, bitumen reflectance; $R_{\mathrm{eq}} \%$, reflectance equivalent calculated from Jacob and Hiltmann's equation (1985) 


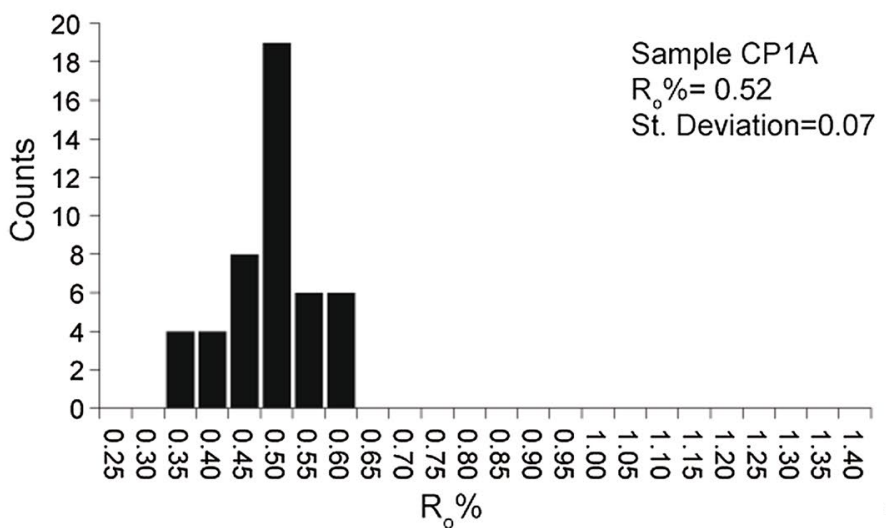

A
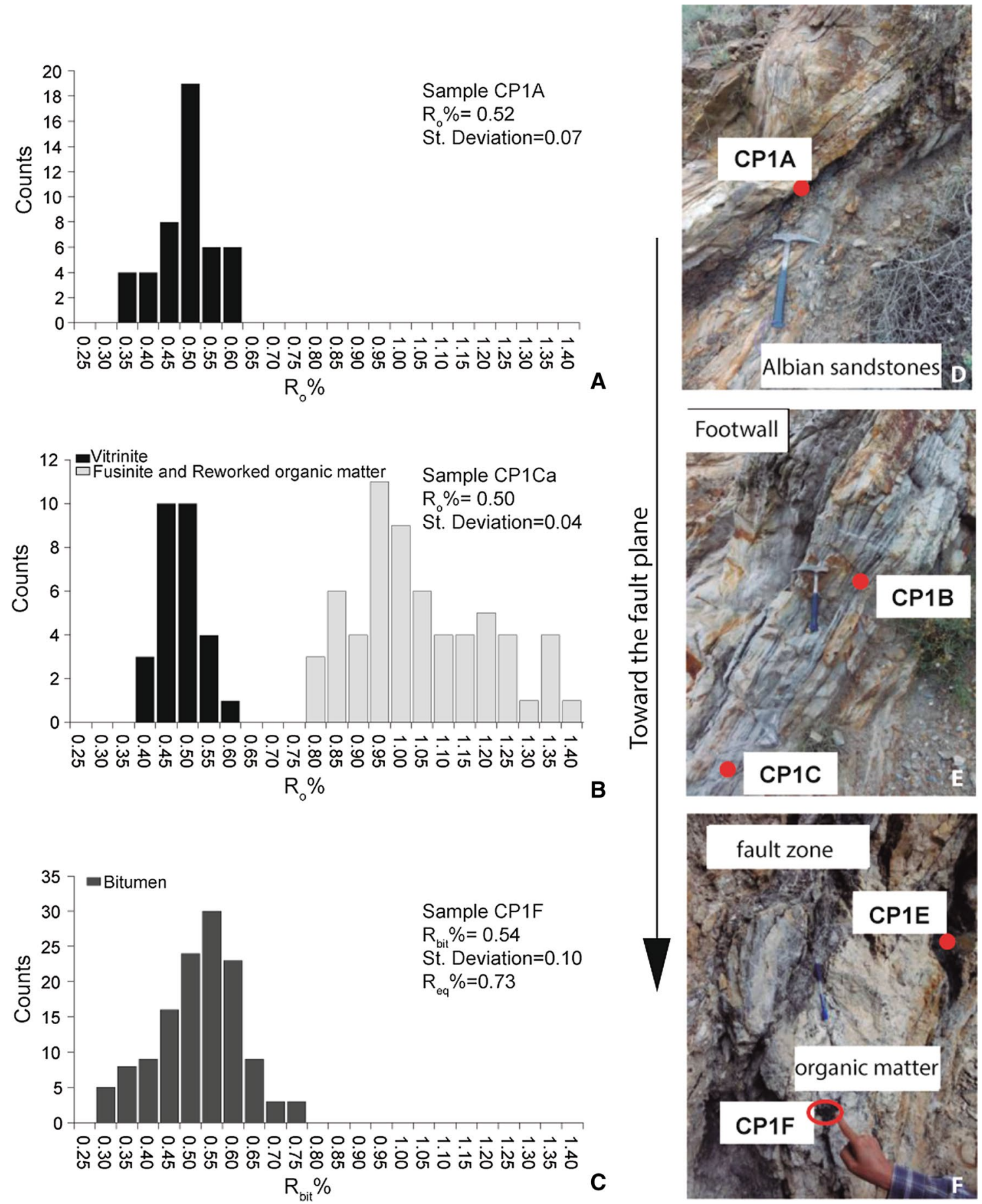

Fig. 8 a-c Representative histograms of distribution of organic matter and bitumen reflectance data. $\mathbf{d}-\mathbf{f}$ Photographs showing the location of the analyzed samples, CP, Préjano

Préjano site). When component $\mathrm{G}$ is calculated, it exhibits reasonably good clustering at the site scale and between different sites (Fig. 15a). The other identified components show mostly scattered distributions, as for example component IT in site PA3 (i.e., Fig. 15b), although some remarkable exceptions have been found in sites FCA8, FCA10, PA5, and PA7 (Fig. 15c-f) and will be interpreted in the next section. 

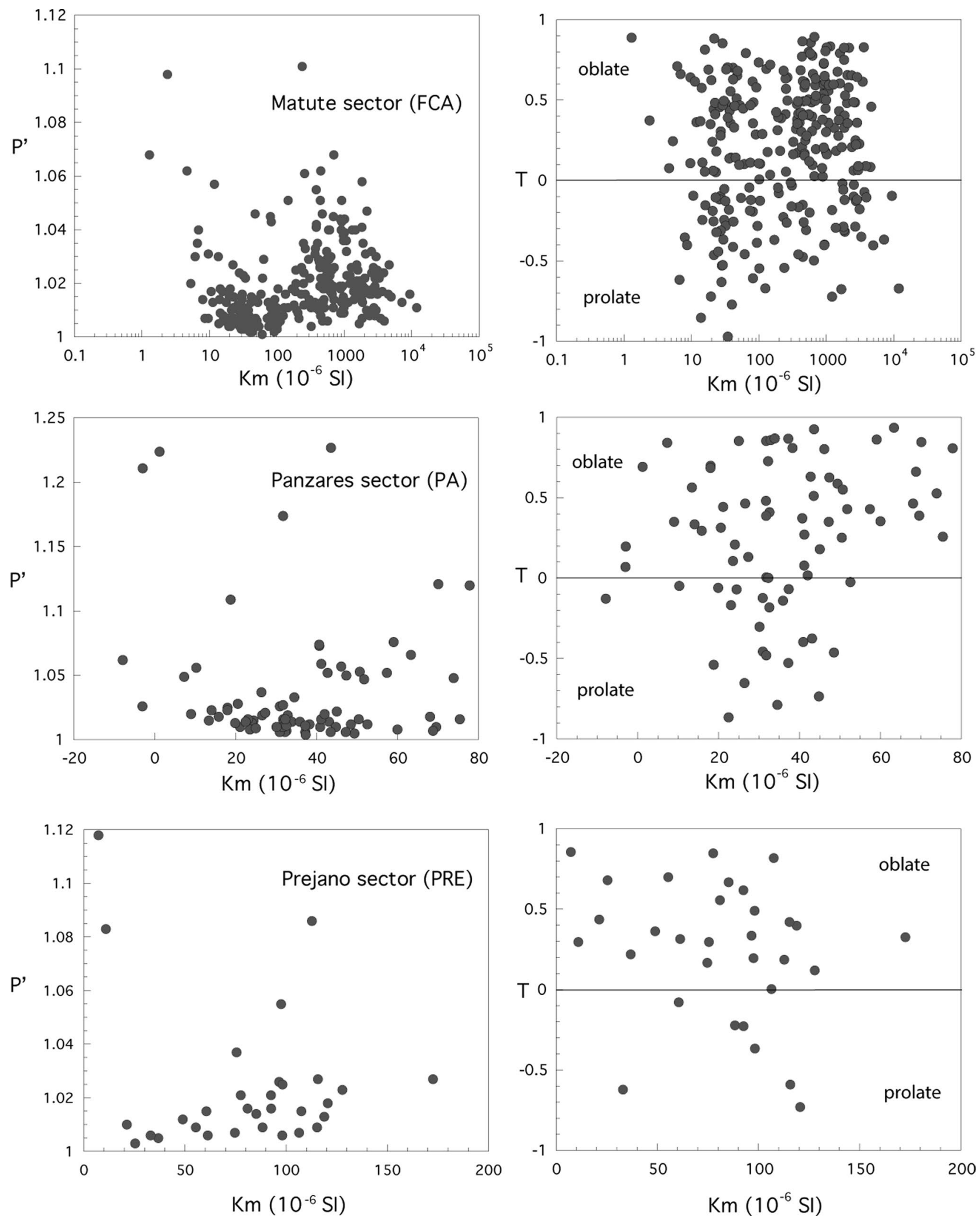

Fig. 9 Corrected anisotropy degree $\left(P^{\prime}\right)$ versus the bulk magnetic susceptibility $(\mathrm{Km})$, and shape parameter (T) versus the bulk magnetic susceptibility $(\mathrm{Km})$ for the total measured samples in the three studied sectors 
Table 3 Summary of magnetic scalar data

\begin{tabular}{|c|c|c|c|c|c|c|c|c|c|}
\hline \multicolumn{2}{|l|}{ Site } & $n / N$ & Unit & $\mathrm{Km}\left(\times 10^{-6} \mathrm{SI}\right)$ & St. dev. $\left(\times 10^{-6} \mathrm{SI}\right)$ & $P^{\prime}$ & St. dev. & $T$ & St. dev. \\
\hline \multicolumn{2}{|l|}{$\begin{array}{l}\text { Hanging wall: } \\
\text { FCA2 + FCA7 }\end{array}$} & $38 / 42$ & Jurassic limestone & 19.6 & 14.7 & 1.017 & 0.020 & 0.056 & 0.524 \\
\hline \multicolumn{2}{|l|}{ FCA6 } & $21 / 21$ & Fault breccia & 21.6 & 10.6 & 1.022 & 0.032 & 0.164 & 0.419 \\
\hline \multicolumn{2}{|l|}{ FCA8 } & $20 / 21$ & Fault breccia & 29.5 & 18.4 & 1.013 & 0.014 & 0.192 & 0.424 \\
\hline \multicolumn{2}{|l|}{ FCA9 } & $17 / 17$ & Fault breccia & 84.9 & 17.4 & 1.007 & 0.004 & 0.164 & 0.360 \\
\hline \multicolumn{2}{|c|}{ Footwall: levels A $+B+C$} & $185 / 186$ & Cenozoic breccia & 1200.0 & 1500.0 & 1.023 & 0.014 & 0.259 & 0.385 \\
\hline FCA10 & Level A & $26 / 27$ & Cenozoic breccia & 327.0 & 223.0 & 1.015 & 0.007 & 0.266 & 0.265 \\
\hline FCA15 & Level A & $29 / 29$ & Cenozoic breccia & 2480.0 & 2180.0 & 1.019 & 0.006 & 0.138 & 0.385 \\
\hline FCA3 & Level A & $26 / 26$ & Cenozoic breccia & 842.0 & 1010.0 & 1.023 & 0.018 & 0.159 & 0.378 \\
\hline FCA4 + FCA11 & Level A & $40 / 40$ & Cenozoic breccia & 1000.0 & 1510.0 & 1.019 & 0.017 & 0.209 & 0.384 \\
\hline FCA12 & Level A & $18 / 18$ & Cenozoic breccia & 1010.0 & 396.0 & 1.030 & 0.012 & 0.361 & 0.314 \\
\hline FCA14 & Level B & $9 / 9$ & Cenozoic breccia & 627.0 & 377.0 & 1.018 & 0.007 & 0.152 & 0.524 \\
\hline FCA16 + 5a & Level B & $11 / 11$ & Cenozoic breccia & 1390.0 & 1270.0 & 1.040 & 0.015 & 0.468 & 0.392 \\
\hline $\mathrm{FCA} 13+5 \mathrm{~b}$ & Level B & $14 / 14$ & Cenozoic breccia & 1940.0 & 1160.0 & 1.023 & 0.007 & 0.473 & 0.336 \\
\hline FCA17 & Level C & $12 / 12$ & Cenozoic breccia & 509.0 & 331.0 & 1.033 & 0.012 & 0.448 & 0.405 \\
\hline PA1 (klippe 1) & & $6 / 8$ & Fault gouge & 54.6 & 17.5 & 1.100 & 0.047 & 0.802 & 0.087 \\
\hline PA2 (klippe 1) & & $9 / 10$ & Fault breccia & 19.4 & 14.2 & 1.054 & 0.071 & 0.401 & 0.490 \\
\hline PA3 (klippe 2) & & $18 / 18$ & Fault breccia & 37.4 & 13.6 & 1.014 & 0.007 & 0.224 & 0.504 \\
\hline PA4 (klippe 2) & & $5 / 6$ & Fault breccia & 38.1 & 24.6 & 1.009 & 0.003 & 0.509 & 0.288 \\
\hline PA5 (klippe 2) & & $9 / 9$ & Fault gouge & 48.4 & 12.2 & 1.052 & 0.017 & 0.399 & 0.183 \\
\hline PA7 (klippe 2) & & $13 / 15$ & Limestone & 23.5 & 13.0 & 1.021 & 0.018 & -0.180 & 0.383 \\
\hline PA6 (klippe 2) & & $11 / 11$ & Conglomerate & 44.2 & 16.3 & 1.017 & 0.007 & 0.098 & 0.275 \\
\hline PRE5 & & $13 / 14$ & Fault breccia & 94.3 & 22.1 & 1.029 & 0.021 & 0.079 & 0.453 \\
\hline PRE4 & & $7 / 7$ & Fault gouge & 36.8 & 25.0 & 1.024 & 0.042 & 0.373 & 0.488 \\
\hline PRE3 & & $10 / 10$ & Fault breccia & 102.0 & 31.1 & 1.012 & 0.007 & 0.358 & 0.330 \\
\hline
\end{tabular}

$n / N$ : number of specimens considered/number of specimens analyzed at each site $\left(\mathrm{N}-\mathrm{n}\right.$ specimens were not considered due to their very high $P^{\prime}$ value); Km: magnitude of the magnetic susceptibility (in $10^{-6} \mathrm{SI}$ ); $P^{\prime}$ : anisotropy degree; T: shape parameter; e: standard error; FCA, Matute; PA, Panzares; PRE, Préjano

\section{Interpretation and discussion}

Both vitrinite reflectance and mixed-layer illite-smectite data are consistent with the shallow depth of the fault surface $(500-600 \mathrm{~m})$ during the process of thrusting, and the provenance of the fault rocks from the footwall (Cenozoic deposits) of the main thrust. However, clay mineralogy also indicates some contribution from deeper levels that could be exhumed during the process of thrusting, since the ramp of the footwall is more than $10 \mathrm{~km}$ long in cross section and cuts across a sedimentary pile $4-5 \mathrm{~km}$ thick (see Figs. 1, 2). The maximum depth to the thrust $(600 \mathrm{~m}$, see "Structural features. Kinematic indicators" section and Fig. 2) can be calculated from the top of deposition during the Cenozoic. However, temperatures probably exceed the ones corresponding to the maturity of organic matter during sedimentation of the Albian sandstones in this area (see reconstruction in Muñoz et al. 1997) according to a normal geothermal gradient $\left(25{ }^{\circ} \mathrm{C} / \mathrm{km}\right.$ depth). These values are much lower than those obtained within the Cameros basin during the rifting stage and only comparable with its southern margin (Omodeo-Sale et al. 2015). In this sense, frictional heating along the thrust surface must be invoked to explain the temperatures obtained. Consistently, in spite of the intensity of deformation, pressure solution is the main deformation mechanism especially in calcareous clasts. Phyllosilicate neo-formation can to some extent explain slaty cleavage in two of the shear zones (Matute and Préjano), although XRD is also consistent with re-orientation of inherited grains according to the shear direction.

AMS results indicate that both para- and ferromagnetic minerals are the carriers of AMS. Low-temperature measurements of AMS and AARM are consistent with directions obtained at room temperature in two out of the three studied sites, thus suggesting that the ferro- and para-magnetic fabrics are largely coincident, at least considering axes orientations. The relationship between directional AMS data and transport direction of thrusts must be interpreted cautiously, as pointed out in previous applications of AMS to fault rocks (Solum and van der Pluijm 2009; Pomella 2014; 
Fig. 10 Temperature-dependent magnetic susceptibility $(k-\mathrm{T})$ curves for samples a PA5-1 (Panzares sector), b PRE3-3 (Préjano sector), and c FCA5-2 (Matute sector)

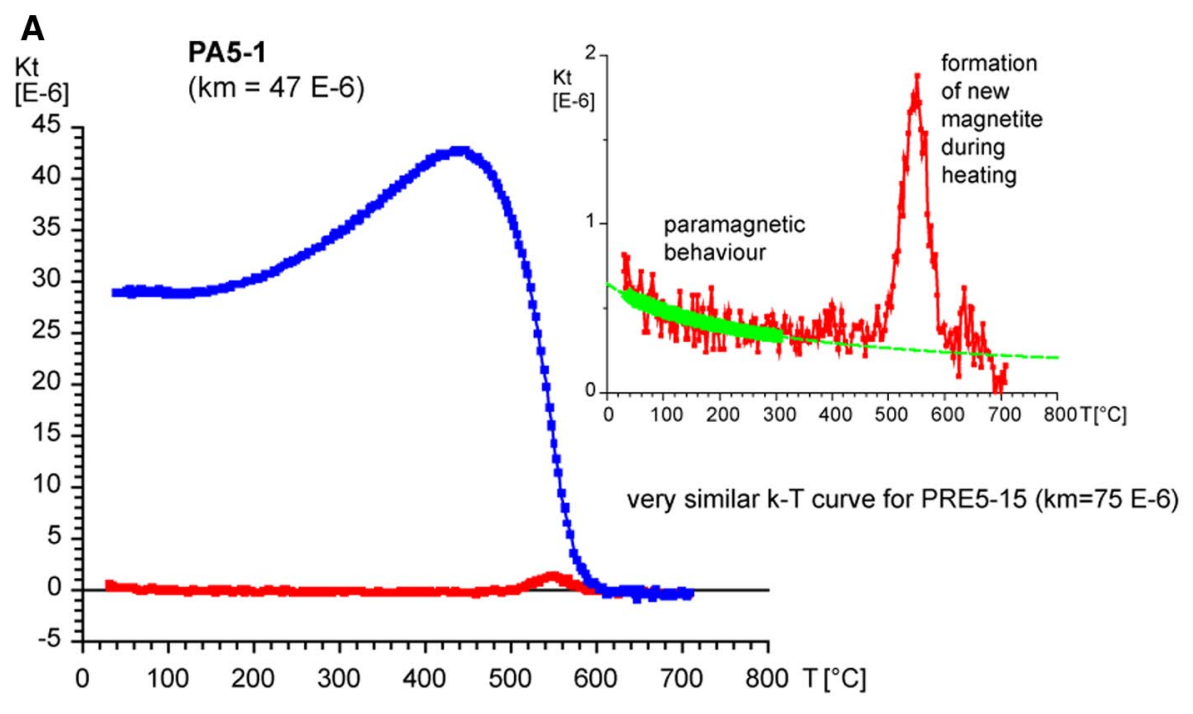

B

Kt

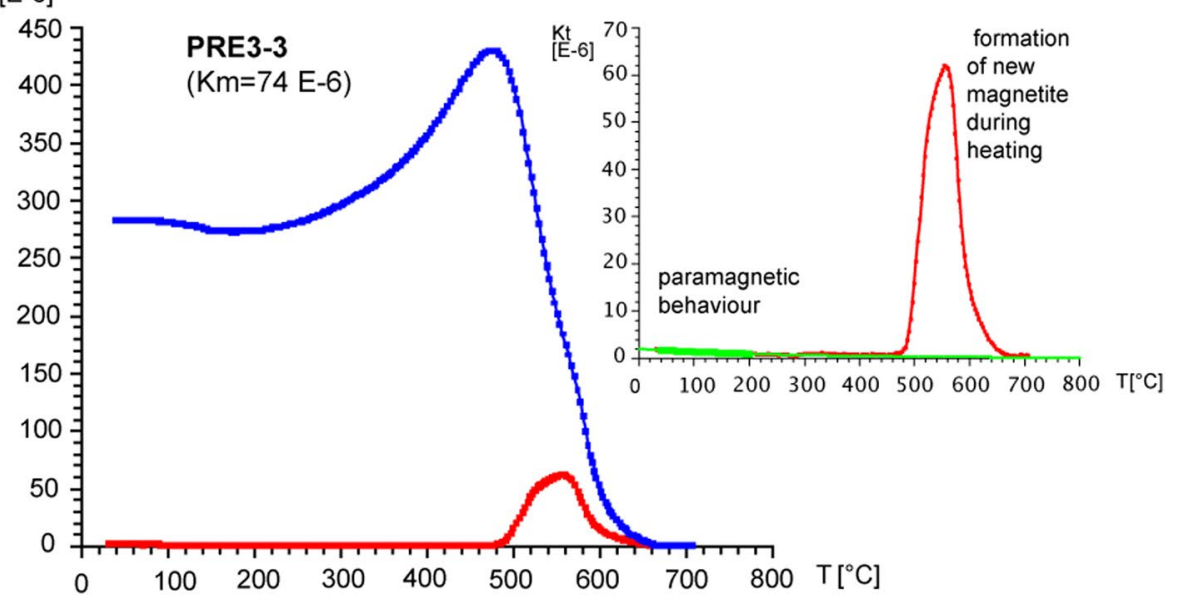

C

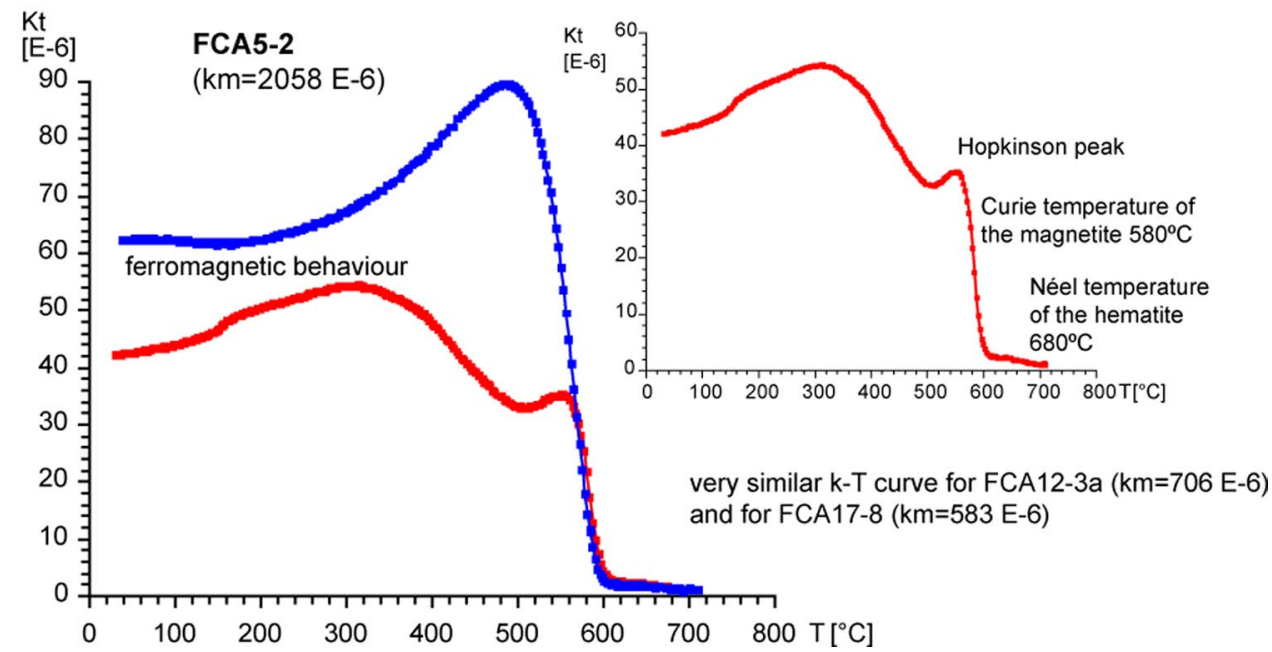



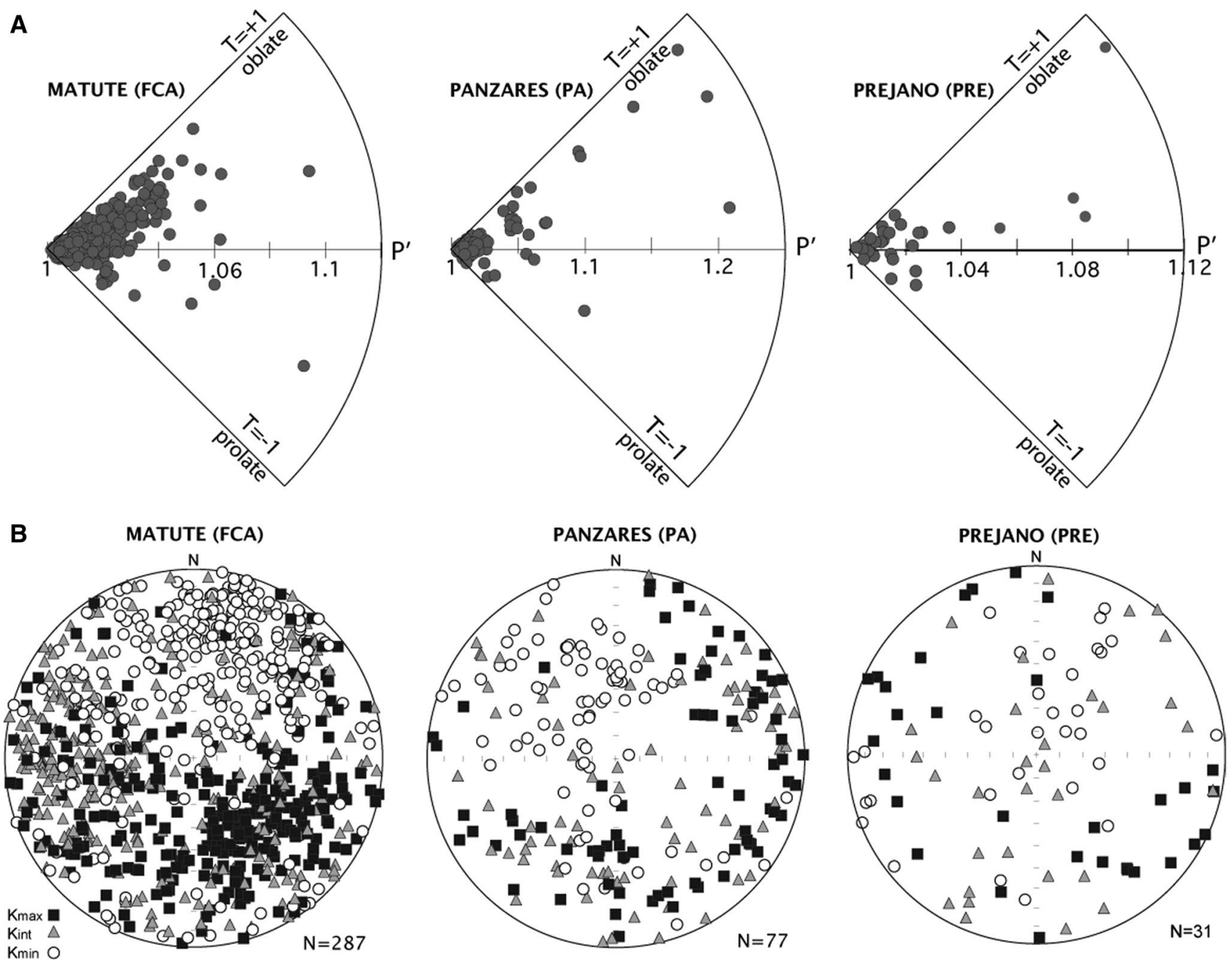

Fig. 11 a Polar plot for the total of measured samples of the shape parameter (T) versus the corrected anisotropy degree $\left(P^{\prime}\right)$ for the three areas. b Lower hemisphere equal area projection of AMS results for the total of measured samples in the three studied sectors

Moreno et al. 2014). In the three sites studied in this work, the magnetic foliation is consistent with the foliation at the outcrop scale (although higher dips for the magnetic foliation are generally observed), consistently with thin sections showing different sets of $\mathrm{C}$ planes in the Panzares area. This difference is probably due to the difficulty of separating $\mathrm{S}$ and $\mathrm{C}$ planes in outcrop observations, what would bias $\mathrm{S}$ populations toward shallower dips.

In the Matute area (FCA sites), the average strike of the magnetic foliation is WNW-ESE, although, as we described in previous sections, in different levels (at different distances from the main thrust, Fig. 12a) of the brecciated unit, this strike changes between NE-SW and WNW-ESE, maintaining in all cases a southward dip. If the transport direction is assumed to be perpendicular to the intersection lineation between $\mathrm{S}$ and $\mathrm{C}$ planes, it shows an average NNW-SSE trend (clear in sites located several meters below the main thrust surface), coinciding with slickenside striations, and shows variations to NW$\mathrm{SE}$ and NE-SW in sites located closer to the thrust. The Jurassic limestones in the hanging wall show in average similar results, but higher scattering, probably due to the magnetic mineralogy and the low degree of deformation. Accordingly, the trend of the mean of magnetic lineations in the footwall (breccia levels A, B, C) is parallel to the transport direction inferred from these kinematic indicators (Figs. 3, 12a). However, its plunge is higher than the one corresponding to the shear direction, because the magnetic lineation is contained within the foliation plane and, interestingly, its projection onto the $\mathrm{C}$ or thrust planes measured in the field parallelizes the transport direction (Fig. 16). This poses a different interpretation for magnetic lineation with respect to previous works, where it is considered to be contained within the shear plane (Parés et al. 1999) or else at intermediate orientations between the $\mathrm{C}$ and $\mathrm{S}$ planes (Aranguren et al. 1996) or at the intersection between both 
Fig. 12 AMS results in the sites of the Matute sector (a), Panzares sector (b), and Préjano sector (c). Lower hemisphere equal area projection

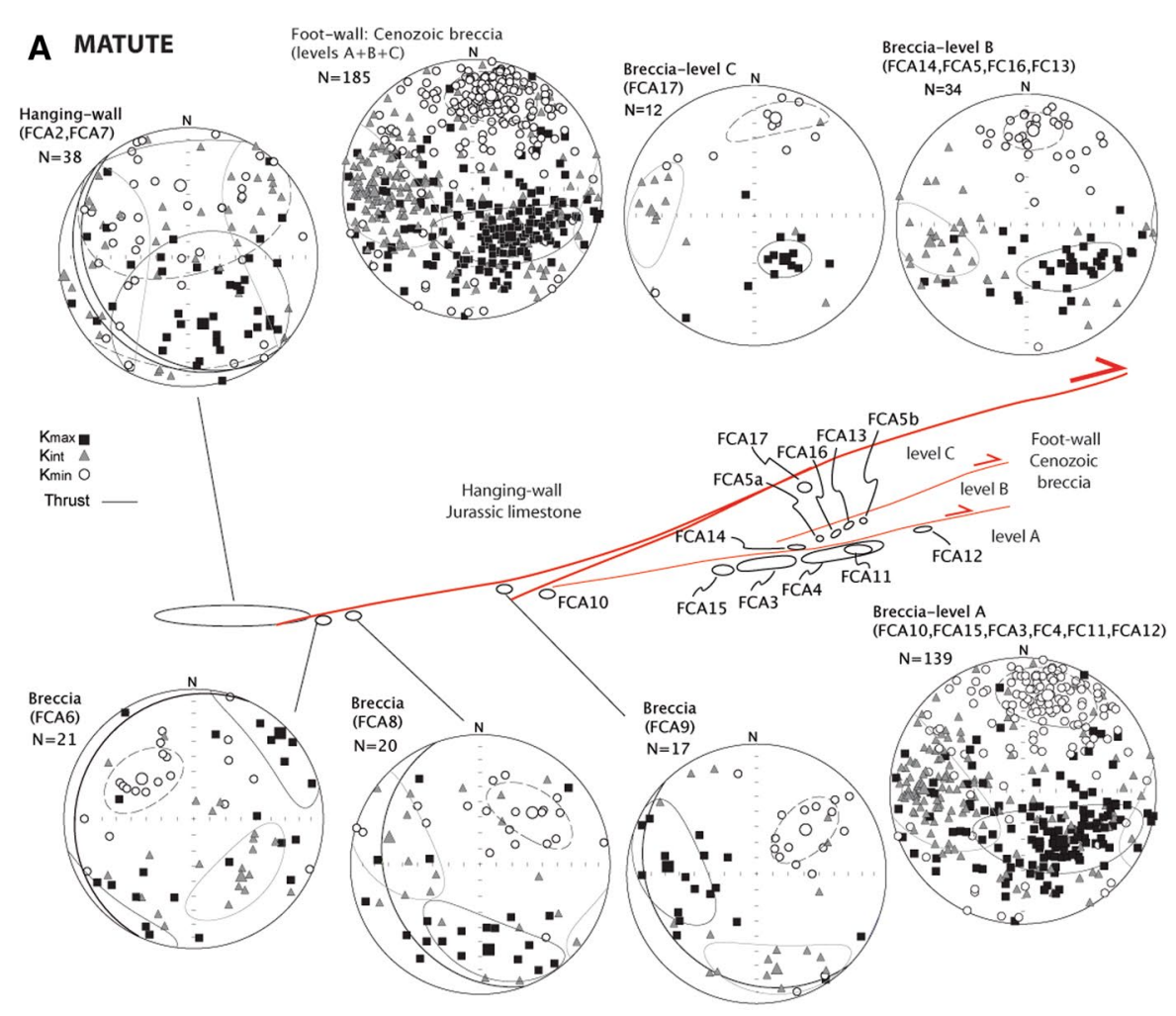

B

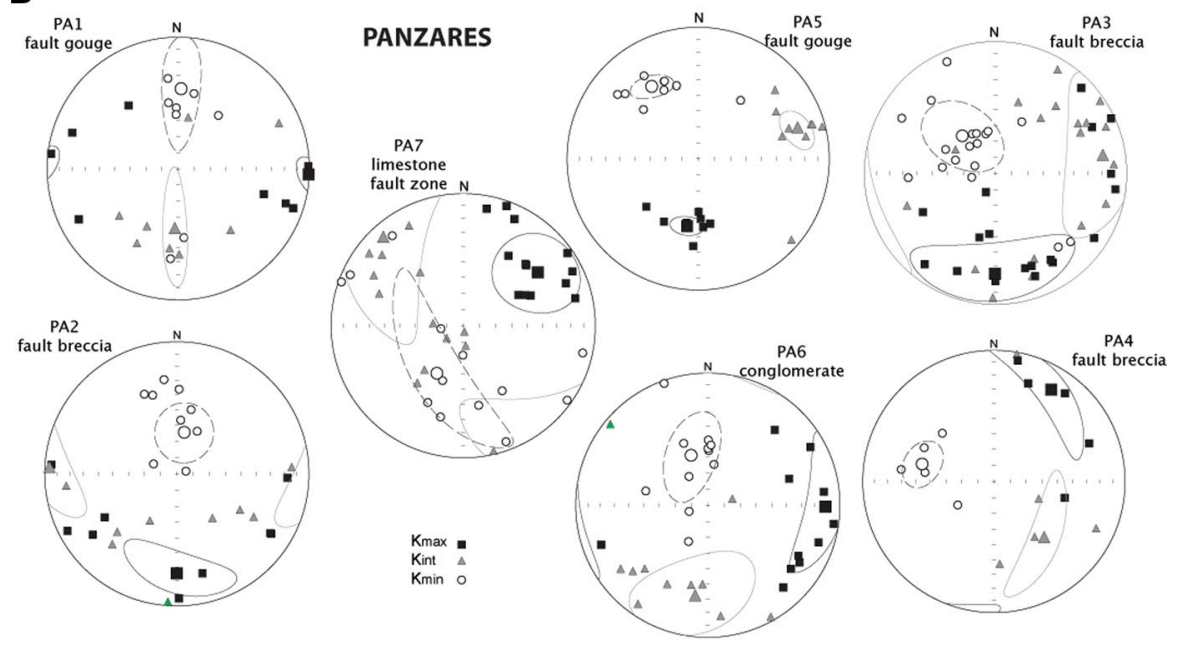

C

PRÉJANO
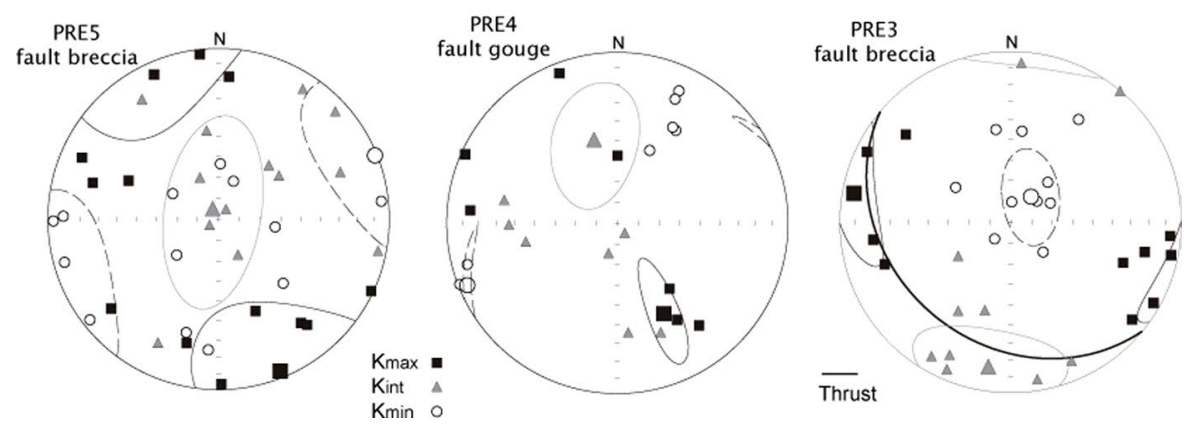
Table 4 Summary of magnetic directional data

\begin{tabular}{|c|c|c|c|c|c|c|c|}
\hline \multicolumn{2}{|l|}{ Site } & $k_{\max }$ dec/inc & Conf. angles & $k_{\text {int }} \mathrm{dec} / \mathrm{inc}$ & Conf. angles & $k_{\min }$ dec/inc & Conf. angles \\
\hline \multicolumn{2}{|c|}{ Hanging wall: FCA2 + FCA7 } & $167 / 46$ & $59 / 53$ & $261 / 3$ & $67 / 53$ & $354 / 43$ & $67 / 57$ \\
\hline \multicolumn{2}{|l|}{ FCA6 } & $045 / 7$ & $39 / 21$ & $141 / 41$ & $37 / 18$ & $308 / 48$ & $26 / 18$ \\
\hline \multicolumn{2}{|l|}{ FCA8 } & $174 / 34$ & $46 / 19$ & $286 / 28$ & $47 / 22$ & $045 / 43$ & $28 / 16$ \\
\hline \multicolumn{2}{|l|}{ FCA9 } & $275 / 32$ & $41 / 22$ & $168 / 24$ & $41 / 18$ & $048 / 48$ & $28 / 14$ \\
\hline \multicolumn{2}{|c|}{ Footwall: levels $\mathrm{A}+\mathrm{B}+\mathrm{C}$} & $141 / 51$ & $48 / 18$ & $267 / 25$ & $48 / 25$ & $011 / 27$ & $25 / 18$ \\
\hline FCA10 & Level A & $187 / 68$ & $57 / 20$ & $087 / 4$ & $60 / 38$ & $355 / 21$ & $49 / 14$ \\
\hline FCA15 & Level A & $159 / 50$ & $21 / 17$ & $275 / 20$ & $21 / 16$ & $019 / 33$ & $17 / 16$ \\
\hline FCA3 & Level A & $160 / 52$ & $37 / 19$ & $288 / 26$ & $36 / 26$ & $031 / 26$ & $27 / 20$ \\
\hline FCA $4+$ FCA11 & Level A & $116 / 33$ & $39 / 24$ & $258 / 51$ & $40 / 33$ & $013 / 18$ & $36 / 26$ \\
\hline FCA12 & Level A & $135 / 49$ & $15 / 8$ & $264 / 28$ & $14 / 8$ & $010 / 26$ & $12 / 7$ \\
\hline FCA14 & Level B & $153 / 45$ & $21 / 12$ & $277 / 29$ & $21 / 13$ & $026 / 31$ & $14 / 12$ \\
\hline FCA16 + FCA5a & Level B & $116 / 36$ & $29 / 11$ & $242 / 39$ & $29 / 14$ & $001 / 30$ & $14 / 11$ \\
\hline FCA13 + FCA5b & Level B & $143 / 61$ & $35 / 12$ & $264 / 16$ & $35 / 15$ & $001 / 23$ & $16 / 12$ \\
\hline FCA17 & Level C & $145 / 56$ & $17 / 12$ & $272 / 22$ & $30 / 17$ & $012 / 24$ & $30 / 10$ \\
\hline \multicolumn{2}{|l|}{ PA1 (klippe 1) } & 092/0 & $32 / 10$ & $182 / 43$ & $32 / 10$ & $001 / 46$ & $11 / 8$ \\
\hline \multicolumn{2}{|l|}{ PA2 (klippe 1) } & $180 / 26$ & $33 / 14$ & $272 / 4$ & $32 / 14$ & $010 / 64$ & $19 / 18$ \\
\hline \multicolumn{2}{|l|}{ PA3 (klippe 2) } & $180 / 24$ & $45 / 21$ & $082 / 18$ & $45 / 25$ & $318 / 59$ & $29 / 19$ \\
\hline \multicolumn{2}{|l|}{ PA4 (klippe 2) } & $032 / 19$ & $42 / 11$ & $139 / 41$ & $41 / 10$ & $284 / 43$ & $15 / 12$ \\
\hline \multicolumn{2}{|l|}{ PA5 (klippe 2) } & $189 / 47$ & $10 / 6$ & $074 / 22$ & $13 / 9$ & $327 / 35$ & $13 / 7$ \\
\hline \multicolumn{2}{|l|}{ PA7 (klippe 2) } & $054 / 31$ & $30 / 23$ & $317 / 12$ & $67 / 24$ & $209 / 56$ & $67 / 16$ \\
\hline \multicolumn{2}{|l|}{ PA6 (klippe 2) } & $091 / 12$ & $37 / 14$ & $188 / 30$ & $39 / 25$ & $341 / 57$ & $30 / 15$ \\
\hline \multicolumn{2}{|l|}{ PRE5 } & $158 / 4$ & $45 / 30$ & $321 / 85$ & $48 / 23$ & $068 / 11$ & $36 / 29$ \\
\hline \multicolumn{2}{|l|}{ PRE4 } & $153 / 40$ & $30 / 7$ & $344 / 49$ & $32 / 20$ & $246 / 5$ & $25 / 2$ \\
\hline \multicolumn{2}{|l|}{ PRE3 } & $280 / 7$ & $31 / 12$ & $189 / 13$ & $30 / 23$ & $039 / 74$ & $23 / 14$ \\
\hline
\end{tabular}

$k_{\max }, k_{\text {int }}, k_{\min }$ mean (trend/plunge) considering the Jelinek statistic, Conf. angles: confidence angles. Sites are arranged in the table sorted by sectors and by their position in the cross sections. FCA, Matute; PA, Panzares; PRE, Préjano

Table 5 Summary of magnetic directional and scalar data for sites analyzed at room (palin text) and low temperatures (italic)

\begin{tabular}{|c|c|c|c|c|c|c|c|c|c|c|c|}
\hline Site & $n$ & $k_{\max }$ dec/inc & Conf. ang. & $k_{\text {int }}$ dec/inc & Conf. ang. & $k_{\min }$ dec/inc & Conf. ang. & $\mathrm{Km} 10^{-6} \mathrm{SI}$ & Km-LT/Km-RT & $\mathrm{Pj}$ & $T$ \\
\hline FCA8-RT & 8 & $159 / 18$ & $23 / 6$ & $267 / 42$ & $24 / 8$ & $052 / 42$ & $15 / 8$ & 33.2 & 1.25 & 1.017 & 0.260 \\
\hline$F C A 8-L T$ & 8 & $244 / 34$ & $46 / 14$ & $026 / 49$ & $46 / 21$ & $140 / 20$ & $24 / 13$ & 41.6 & & 1.008 & -0.166 \\
\hline FCA9-RT & 6 & $258 / 34$ & $24 / 21$ & $159 / 13$ & $25 / 11$ & $052 / 52$ & $23 / 12$ & 95.9 & 1.62 & 1.007 & 0.192 \\
\hline$F C A 9-L T$ & 6 & $297 / 20$ & $36 / 9$ & $192 / 34$ & $35 / 26$ & $052 / 49$ & $27 / 11$ & 156.0 & & 1.012 & 0.414 \\
\hline FCA15-RT & 6 & $163 / 62$ & $38 / 18$ & $283 / 15$ & $38 / 13$ & $020 / 23$ & $20 / 13$ & 1540.0 & 0.96 & 1.018 & 0.276 \\
\hline FCA15-LT & 6 & $140 / 55$ & $26 / 12$ & $279 / 28$ & $23 / 13$ & $019 / 19$ & $26 / 17$ & 1480.0 & & 1.019 & 0.124 \\
\hline FCA5-RT & 4 & & & & & & & 2390.0 & 0.92 & 1.024 & 0.099 \\
\hline$F C A 5-L T$ & 4 & & & & & & & 2190.0 & & 1.026 & 0.313 \\
\hline PA3-RT & 6 & $168 / 17$ & $82 / 11$ & 077/06 & $82 / 7$ & $327 / 72$ & $12 / 4$ & 39.2 & 1.42 & 1.014 & 0.477 \\
\hline$P A 3-L T$ & 6 & $128 / 21$ & $54 / 5$ & $220 / 05$ & $54 / 6$ & $322 / 68$ & $14 / 4$ & 55.8 & & 1.014 & 0.109 \\
\hline PA5-RT & 6 & $192 / 45$ & $11 / 8$ & $071 / 27$ & $14 / 9$ & $322 / 32$ & $10 / 10$ & 49.4 & 1.52 & 1.049 & 0.340 \\
\hline$P A 5-L T$ & 6 & $187 / 49$ & $12 / 6$ & $065 / 25$ & $14 / 9$ & $319 / 30$ & $13 / 9$ & 74.9 & & 1.042 & 0.482 \\
\hline PRE5-RT & 4 & & & & & & & 89.5 & 2.84 & 1.034 & 0.126 \\
\hline PRE5-LT & 4 & & & & & & & 254.0 & & 1.031 & 0.353 \\
\hline
\end{tabular}

$n$ number of analyzed samples, $k_{\max }, k_{\text {int }}, k_{\min }$ mean (trend/plunge) considering the Jelinek statistic, Conf. angles confidence angles, Km magnitude of the magnetic susceptibility (in $10^{-6} \mathrm{SI}$ ), Km-LT/Km-RT ratio of magnetic susceptibility at low temperature and at room temperature, $P^{\prime}$ anisotropy degree, T shape parameter. FCA, Matute; PA, Panzares; PRE, Préjano 


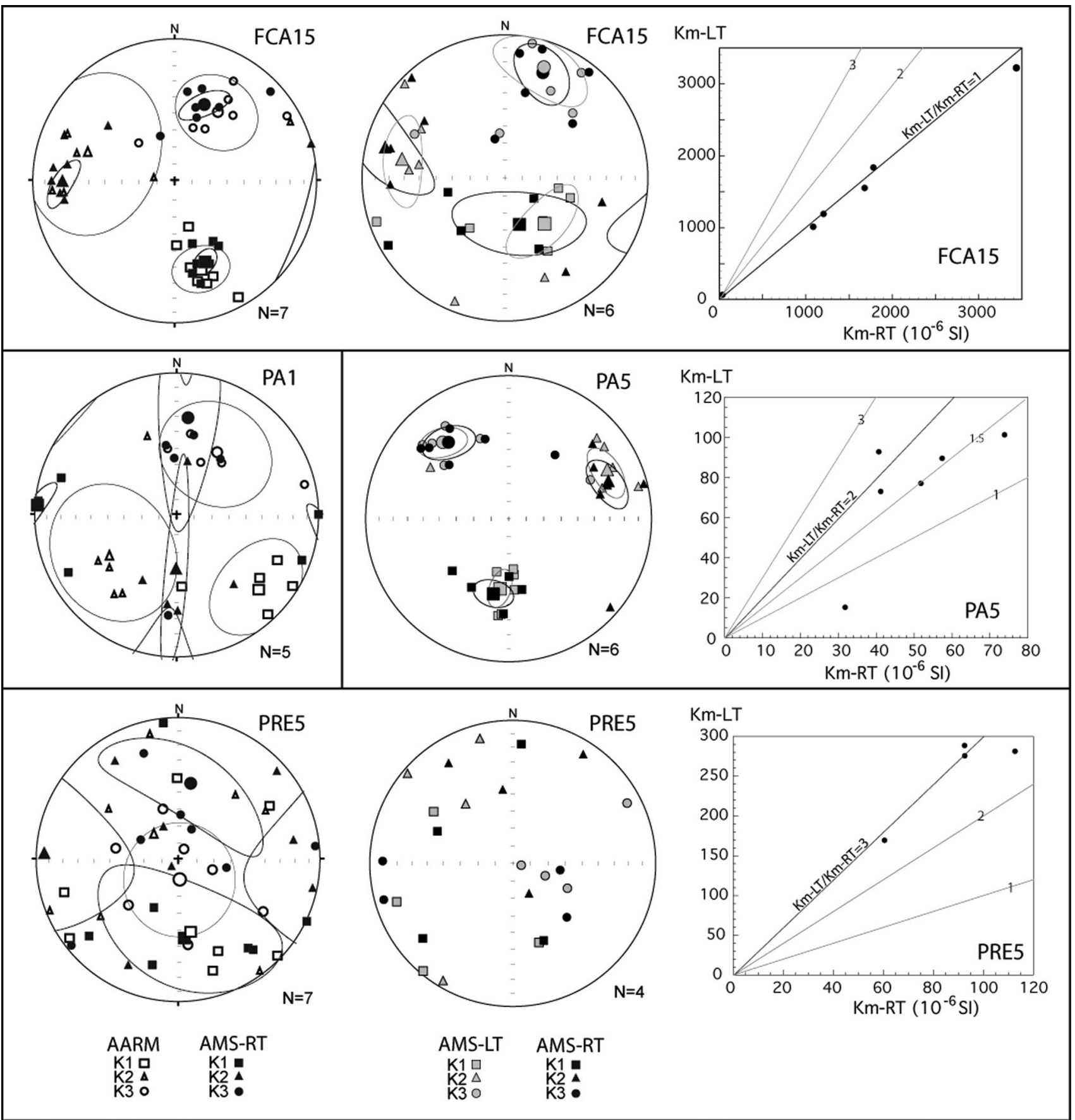

Fig. 13 Lower hemisphere equal area projection of AARM results (white symbols), AMS results at room temperature (black symbols), and AMS results at low temperature (gray symbols). Diagrams of

sets (Solum and van der Pluijm 2009). Probably, the shallow depths and the particular conditions of deformation in the Cameros-Demanda thrust are responsible for the non-migration of the magnetic lineation from the $\mathrm{S}$ to the $\mathrm{C}$ planes in the shear band. In this sense, the possibility of calculating the shear direction by means of AMS even in sites where orientations of foliation planes are not evident, magnetic susceptibility at room temperature (Km-RT) versus magnetic susceptibility at low temperature (Km-LT)

or cannot be reliably measured, widens its field of application as a kinematic indicator.

In the Panzares area (PA sites), magnetic foliation shows shallower dips and stronger scattering, in accordance with foliation (S) and shear (C) plane attitudes measured in the outcrops. However, individual sites show good clusters of $k_{\min }$, and the reason for variations between sites is their 
Fig. 14 Orthogonal, thermal demagnetization diagrams showing the orientation of the remanent magnetization at heating steps. Black (white) represents horizontal (vertical) projection of the vector. Components distinguished considering the unblocking temperature spectrum: $\mathrm{G}$, unblocking temperature below $150{ }^{\circ} \mathrm{C}$; LT, $150^{\circ}-350{ }^{\circ} \mathrm{C}$; IT, $350^{\circ}-580^{\circ} \mathrm{C}$; HT, maximum unblocking temperatures higher than $600{ }^{\circ} \mathrm{C}$. The decay of the NRM is also represented. FCA, Matute; PA, Panzares
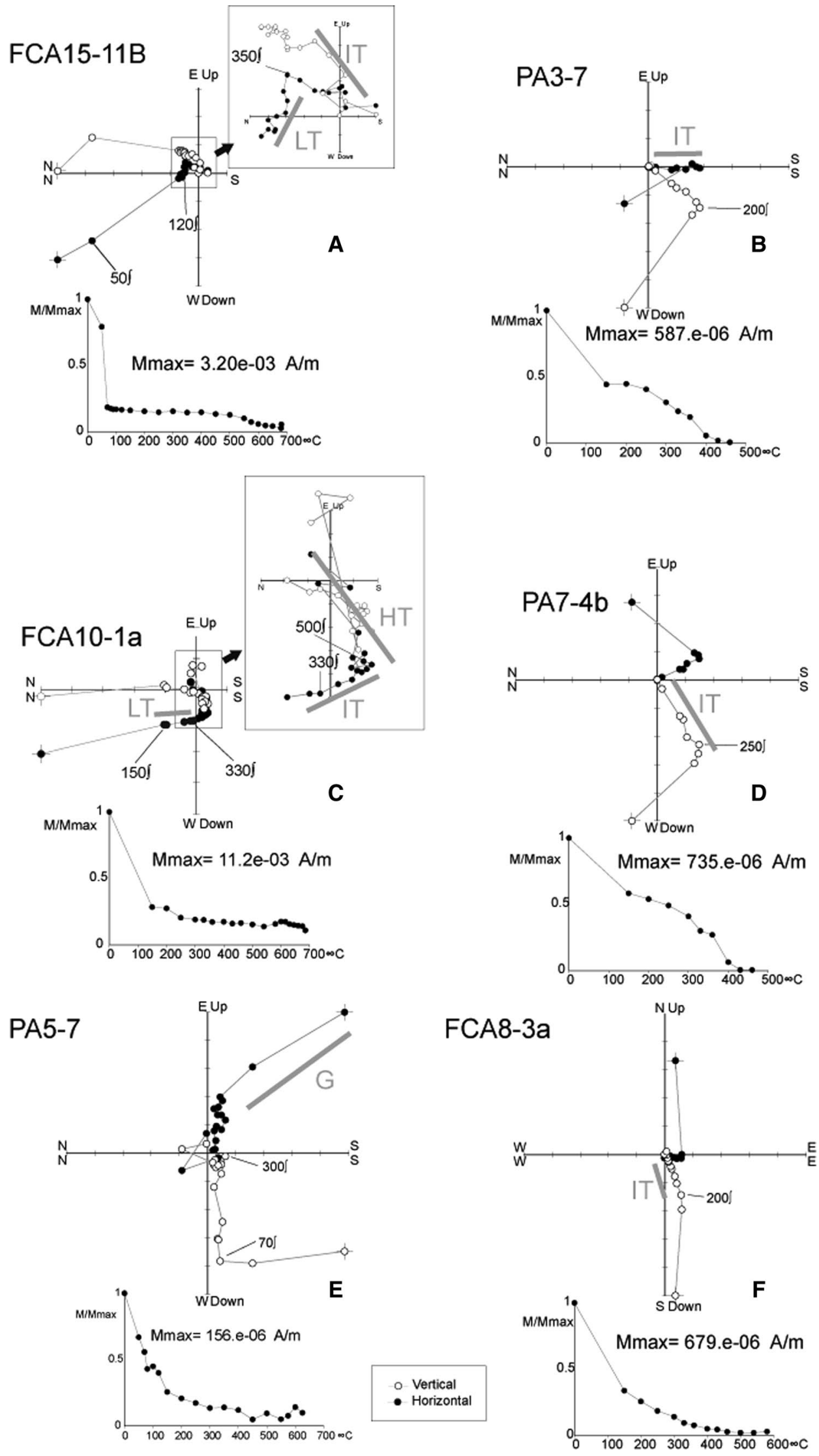
Fig. 15 Lower hemisphere equal area projection of the characteristic components calculated for different sites. Black (white) represents lower (upper) hemisphere. a Characteristic component $\mathrm{G}$ (unblocking temperature below $150{ }^{\circ} \mathrm{C}$ ) for different sites. b Characteristic component IT (unblocking temperature between 350 and $580^{\circ} \mathrm{C}$ ) for PA3. c Characteristic component LT (unblocking temperature between 150 and $350{ }^{\circ} \mathrm{C}$ ) for FCA10. d Characteristic component IT for PA7. e Characteristic component IT for PA5. f Characteristic component IT for FCA8. g Characteristic components IT or LT for different sites. $\mathbf{h}$ Theoretical model for the deflection of a paleomagnetic vector originally oriented according to the Cenozoic magnetic field after applying simple shear deformation according to the transport direction of the Cameros thrust in the Panzares and Matute areas. The fields of compatibility for the initially normal and reverse field directions are shown. See text for further explanation
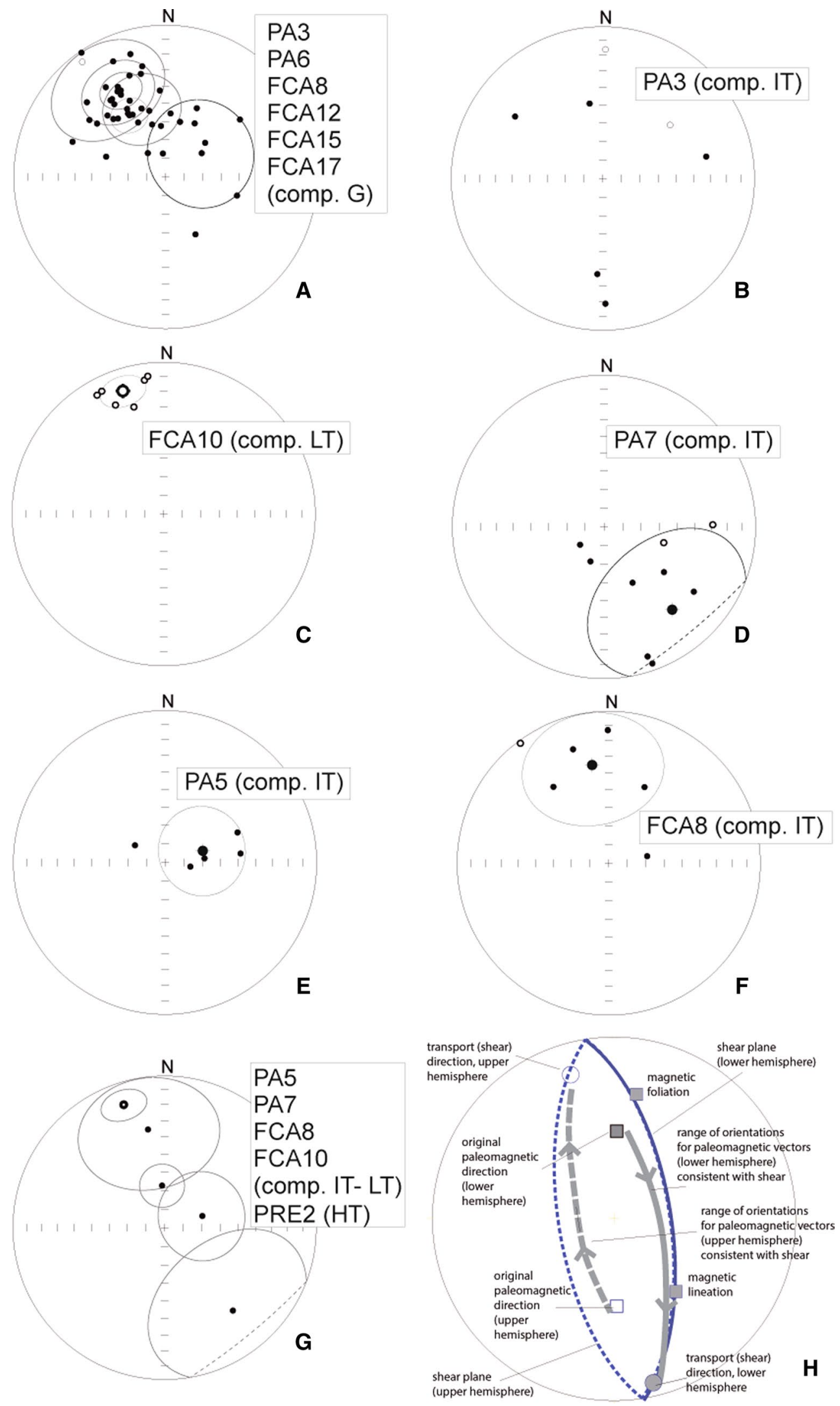
location in the different klippen, as confirmed by changes in the orientation of cleavage between sites. A dominant $\mathrm{E}-\mathrm{W}$ strike and a slight deviation toward the NNW of its poles (Fig. 16) can be defined. Lineations are scattered within the foliation planes, showing, in individual sites, a trend (1) perpendicular to the slickenside striations (locally parallel to the intersection lineation between $\mathrm{C} 1$ and $\mathrm{C} 2$ planes, PA1, PA4, PA6, PA7), (2) parallel to the transport direction (considering this as the perpendicular to the average $\mathrm{C} 1 / \mathrm{C} 2$ intersection, PA5), or (3) both orientations (PA2, PA3). The different generations of $\mathrm{C}$ planes observed in thin sections can also account for deflecting magnetic lineation orientation toward the intersection lineation (see Debacker et al. 2009; Haerinck et al. 2015) versus the elongation or transport direction within the shear zone. No lithological control seems to exist on this difference because both features are found in argillaceous fault gouge and fault breccia.

In the Préjano area, magnetic foliation shows an average NW-SE strike (parallel to the main thrust) and variable dips to the south, from horizontal to vertical. It is parallel to foliation planes (subvertical, see Fig. 5c), the shear planes, or intermediate between them. The magnetic lineation is scattered within a girdle parallel to the main thrust, with a maximum parallel to its strike.

In summary, the results concerning AMS in the Cameros-Demanda thrust indicate that magnetic lineation can neatly define the transport direction of thrusts (Matute area) or can be scattered approaching the intersection lineation between shear and foliation planes (Préjano area). At an intermediate situation, in the Panzares area, the magnetic lineation shows moderate dispersion and two main populations (parallel and perpendicular to the transport direction). Ambiguities in the interpretation increase when the number of data (i.e., PA sites) does not allow to produce robust clusters, although the intensity of shear deformation (see interpretation of paleomagnetic data below) and lithology probably are controlling factors. In our case, the increase in the ferromagnetic contribution (higher in the Matute sites with respect to the other two) to susceptibility improves the meaning of magnetic lineation as an indicator of the transport direction (an interpretation that can also be derived from Oliva-Urcia et al. 2009). Magnetic foliation is usually better clustered than lineation but does not allow to directly infer the transport direction unless the S/C intersection lineation is extrapolated to magnetic data (i.e., this intersection lineation cannot be considered horizontal by default). Another interesting point is that the shallow P-T conditions in the studied cases (consistent with the occurrence of these structures in modern units within the filling of the Rioja Trough, Muñoz-Jiménez and Casas-Sainz 1997) for the development of magnetic fabrics indicate that deep diagenesis or
Fig. 16 Synthetic stereographic projection and conceptual sketch showing the orientation of the kinematic indicators observed in the outcrops for the three studied areas. The orientation of the axes of the magnetic ellipsoid is also shown. See text for further explanation

wholesale fluid circulation is not necessary to modify the magnetic fabric, provided that deformation is strong and that microbreccia or fault gouges are formed.

An interesting question that arises at this point is the time span during which deformation, and thus magnetic fabrics, developed, and consequently the representativity of AMS data with respect to the whole movement history of the thrust. It must be said that the same question applies to structural data, especially structures developed along surfaces (i.e., slickenside striations) and non-penetrative at the scale of volumes of rocks. Kinematic indicators (here including AMS) may have different temporal meaning according to the provenance of fault rocks (Fig. 17) and the occurrence of syn-tectonic sedimentation in the footwall of the thrust:

1. When fault rocks are derived from the hanging wall of the thrust, in most cases the recorded deformation averages all the displacement directions during the thrust movement, especially if deformation is homogeneous. Even in the case of heterogeneous deformation, if it varies gradually within the shear zone (from top to bottom or vice versa), it will presumably record, with different intensity, this average transport direction.

2. A different scenario appears when heterogeneous deformation and strain partitioning occurs within the shear zone. In this case, the different segments active during different intervals will record different transport directions, whose vectorial sum should equal the average transport direction.

3. When fault rocks are derived from the footwall of the main thrust but only involve the pre-tectonic sedimentary sequence, the spatial-chronological relationships within the fault zone are similar, although the geometry of the shear zone can vary depending on the rheology of the sedimentary pile in the case of upward-decreasing shortening (hanging-wall anticline, see Fig. 17). The Préjano area could be assimilated to this case because the erosion level is below the syn-tectonic sediments exposed in the Arnedo anticline. In this case, the fault rocks would be recording an averaged transport direction for the thrust.

Geometry and deformation record in the shear band change dramatically when deformation is measured in the syn-tectonic sediments occurring in the footwall. We have considered here two possible geometries with two different kinematics each: 


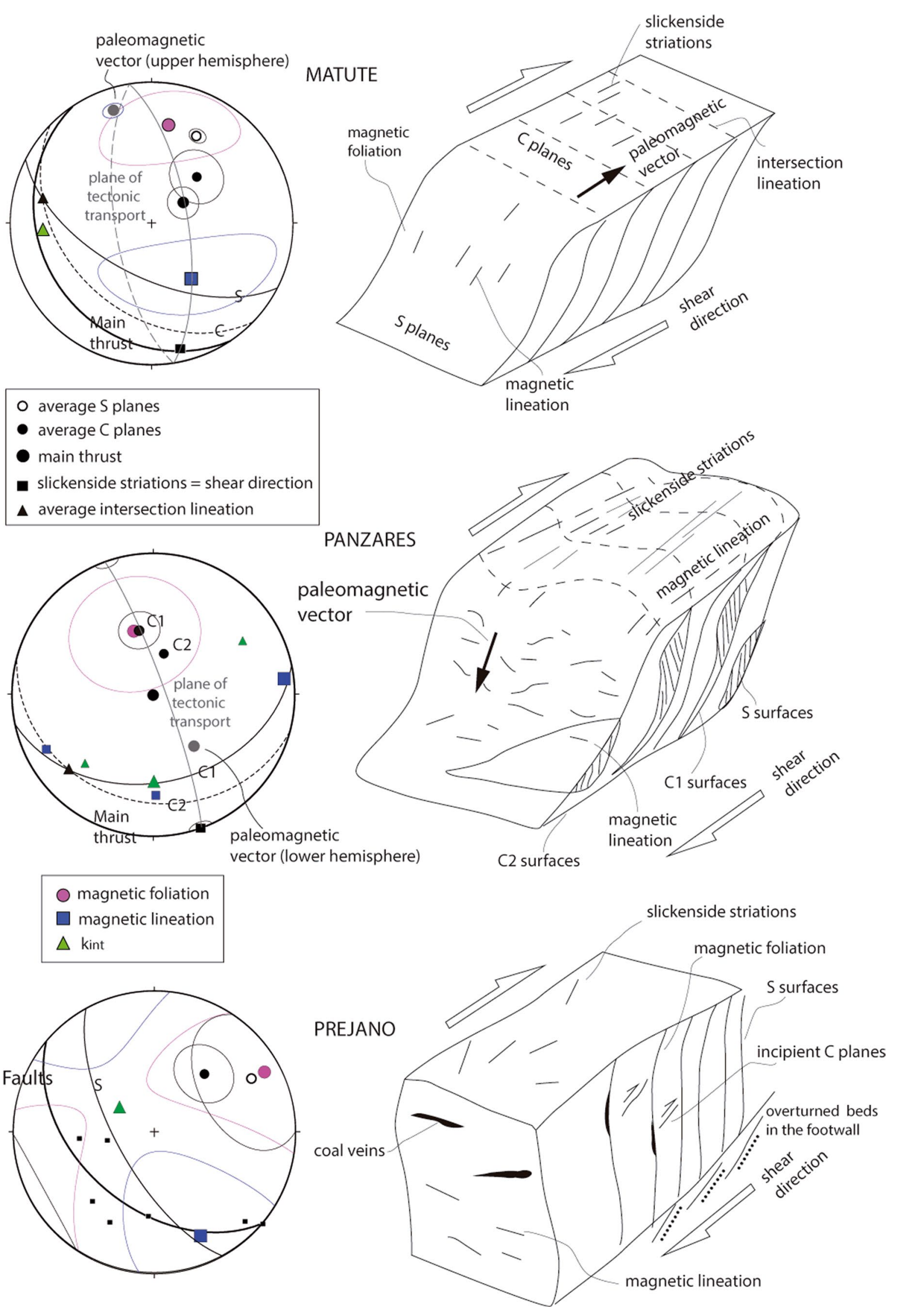


4. Hinterland-migrating deformation within the shear zone. Inactive segments of the shear band are uncomformably covered by successive syn-tectonic units in the footwall of the thrust. Transport directions recorded in each of these units correspond to the sequential evolution of thrust movements, although the segments of the shear band within a particular unit closer to the main fault can also record subsequent movements.

5. Constant width of the shear zone. In this case, deformation progressively diminishes upward within the syn-tectonic filling, but in spite of being less well defined, in each unit the transport direction averages deformation occurring during and after the deposition of the corresponding sedimentary unit. This situation is equivalent to the Matute and the Panzares areas, which only record the kinematics of the thrust postdating the upper part of R3 unit (Upper Oligocene, Muñoz-Jiménez and Casas-Sainz 1997). Accordingly, the studied structures provide a reasonable mean of the kinematics of the thrust from the Late Oligocene to the Late Miocene. However, the case of the Panzares area can be more complicated because part of the displacement of the hanging wall used the Upper Triassic as a décollement and therefore deformation was not completely transferred to the footwall.

The analysis of paleomagnetic data in fault rocks indicates a different meaning of components of NRM in the different sites and specimens. In most cases, the directions corresponding to a specific component (same temperature spectra) in different specimens are scattered. Conversely, a low-temperature component, probably carried by goethite, presents reasonable grouping and probably is a remagnetization linked to thrust movements. The same interpretation can be suggested for sites from the three areas (FCA8, FCA10 in Matute, PA5 and PA7 in Panzares, and PRE2 in Préjano) in which low (LT), intermediate (IT), and high (HT) unblocking temperature components show grouped distributions. These overall, rather poor, results are in contrast to widespread remagnetizations linked to thrusting found in other areas, as for example, the Pyrenees, where systematic remagnetization accompanied the movement of Eocene submarine thrusts (Oliva-Urcia and Pueyo 2007; Oliva-Urcia et al. 2008). This difference is in accordance with paleothermal indicators in the Cameros area that suggest shallow depths and temperatures during the deformation process, not exceeding $3.5 \mathrm{~km}$ and $110{ }^{\circ} \mathrm{C}$, respectively. All in all, local remagnetizations seem necessary to explain the paleomagnetic directions obtained, carried by magnetite in zones of fault gouge and by goethite in breccia and microbreccia units. In breccia units resulting from shear deformation of conglomerates (mostly Matute area), remagnetization was probably precluded by the strong magnetic signal in limestone pebbles, inherited from the Cretaceous remagnetization (see Villalaín et al. 2003; Mata et al. 2006), and difficult to modify by chemical processes. To a limited extent, strain of frictional heating near the fault surface could be responsible for local remagnetizations found in the matrix.

Some geometrical features of particular paleomagnetic components are worth mentioning, specifically the clearly defined paleomagnetic vectors in two sites from Matute (FCA8: $D=350^{\circ} / I=35^{\circ} / \alpha_{95}=34^{\circ}$; FCA10: $D=342^{\circ} / I=-16^{\circ} / \alpha_{95}=10^{\circ}$ ) and other two from Panzares (PA5: $D=73^{\circ} / I=69^{\circ} / \alpha_{95}=24^{\circ}$; PA7: $\left.D=141^{\circ} / I=30^{\circ} / \alpha_{95}=41^{\circ}\right)$ areas. These paleomagnetic vectors are difficult to explain according to simple horizontal- or vertical-axis rotations, but can be deciphered considering the direction and amount of shear deformation that can produce rotations at the grain scale and therefore deformation of paleomagnetic vectors (Lowrie et al. 1986; Kligfield et al. 1983; Cogné and Perroud 1985; Borradaile 1997; Oliva-Urcia et al. 2010c). The analyzed rocks underwent an amount of shear of about $3 \mathrm{~km}$ in a band less than $30 \mathrm{~m}$ thick in average in the Matute area, and thinner in Panzares, giving shear angles close to $90^{\circ}$. Since in this particular case the original orientation of the paleomagnetic vector approaches the shear plane (defined by $k_{\max }$ and $k_{\min }$ axes of the AMS ellipsoid, Fig. 16), the vector would approach the shear direction within this plane during progressive deformation (see Ramsay 1967, p. 129 and ss.). Magnetic grains probably formed with the two possible polarities during the Late Oligocene-Miocene and were subsequently deformed by wholesale shear and grain rotation, in an efficient way that allowed for reorientation of paleomagnetic vectors. Therefore, a priori uninterpretable, but well defined, directions can be considered in light of the strong shear deformation underwent by fault rocks. Under these circumstances, paleomagnetism becomes a sound kinematic indicator, but hinders the possibility, for example, of dating fault rocks by means of the orientation of paleomagnetic vectors associated with remagnetizations.

At the regional scale, the two main transport directions obtained from structural features, AMS and paleomagnetism (NE for the Préjano area and N-NNW for the Matute and Panzares areas), can be either related to (1) two of the main compression directions referred to in the Iberian Chain (NE-SW and NNW-SSE) from paleostress analysis and relationships with tectono-sedimentary Cenozoic units (Capote et al. 2002; Simón and Liesa 2011), or (2) to changes in transport direction in the different thrust sheets related to different dips of the thrust surface (CasasSainz and Simón-Gómez 1992) and, eventually, partitioning of deformation. The former authors attribute the change in translation vectors to the different compression directions resulting from the stress field transmitted from the 


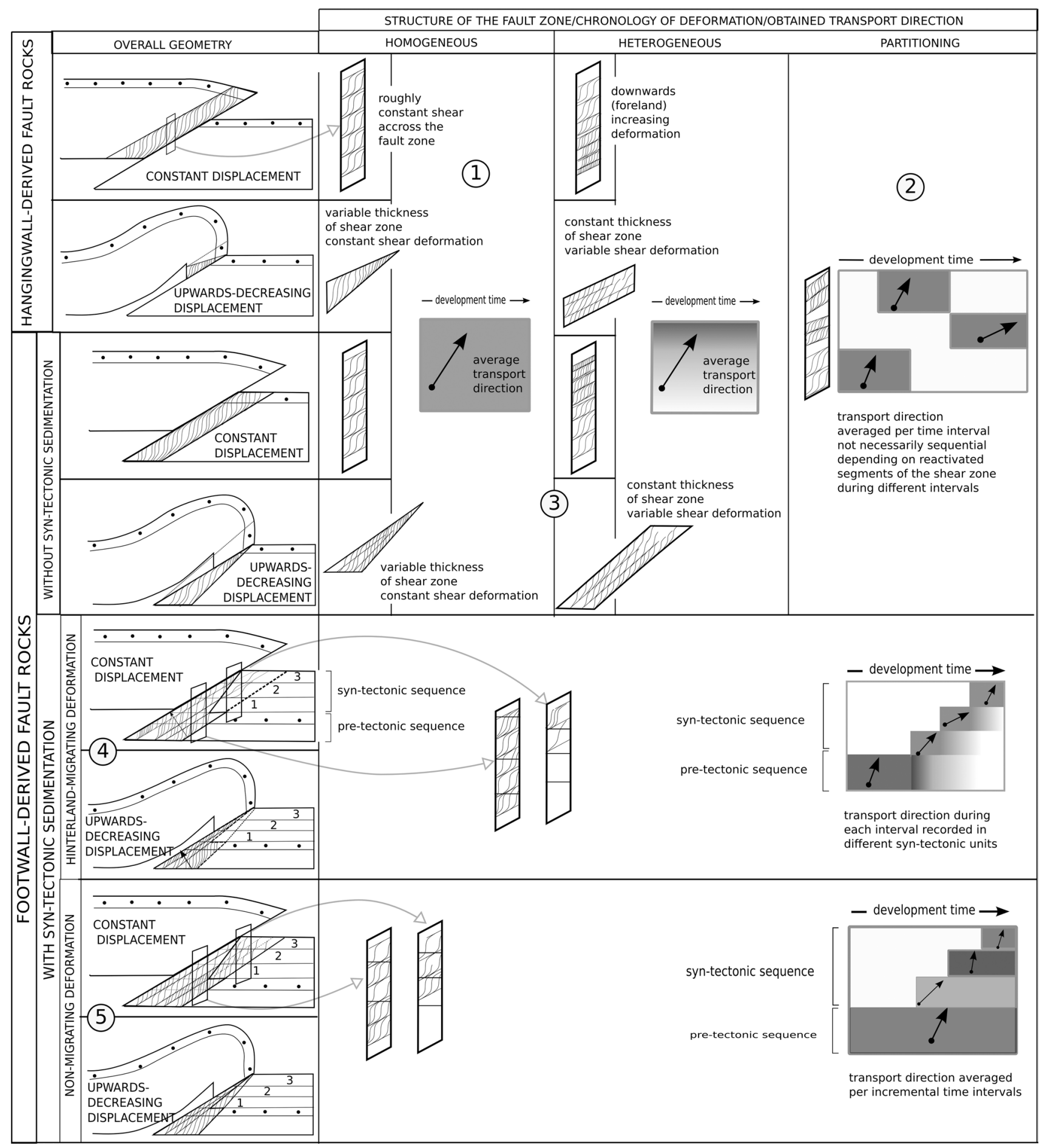

Fig. 17 Idealized behavior of shear zones associated with thrusts, indicating the time span corresponding to the development of magnetic and structural fabrics. Simplifying assumptions include that all the displacement along the main thrust is translated into deformation within the shear zone. Hence the apparently contradictory shape of the shear wedge, whose thickness diminishes upwards, in the same sense that the displacement along the main thrust in cases having a hangingwall anticline. Although a detachment level at the base of the series in the fold models can be considered, in these models friction and displacement are constant throughout the sedimentary pile. See text for detailed explanation 
boundaries of the Iberian plate. However, the change from a main thrust component to reverse-strike-slip component along fault surfaces is not only a matter of compression or shortening directions. It is possible to change the direction of movement of a thrust (the Cameros-Demanda thrust in this case study) maintaining the direction of shortening and changing the axes ratio of the stress ellipsoid (Casas et al. 1992). Transport direction can also vary through time according to the boundary conditions imposed by erosion and sedimentation. Analogue models with sandsilicone systems (Barrier et al. 2002; Pichot and Nalpas 2009) indicate that the geometry of thrusts changes due to syn-tectonic sedimentation at its front, usually developing steeper thrust surfaces. Associated changes in transport direction have not been analyzed yet, but at certain obliquities between the shortening direction and the strike of thrusts, the increase in dip of the thrust surface could favor, from the mechanical point of view, stronger strikeslip versus dip-slip components. In our opinion, the most feasible explanation is that, even in the absence of verticalaxis rotations, different thrust sheets can show different displacement directions (and magnitudes) whose vectorial sum is the average $\mathrm{N}$-directed movement for the main Cameros-Demanda thrust, consistent with kinematic indicators in most part of the thrust front. The NNW-directed movement in the blind thrust below the Arnedo anticline (see cross "Methods" section in Fig. 2) for most of its displacement can combine with the NE-directed, smaller displacement of the secondary thrust in the Préjano area to finally match with the N to NNW thrusting of the Cameros block with respect to the Ebro basin that would represent the main transport direction since the Late Oligocene.

\section{Conclusions}

In this work, mineralogical, organic petrographic, magnetic, and structural techniques were applied to unravel the kinematics of the Cameros-Demanda thrust, one of the most important Cenozoic intraplate thrusts within the Iberian plate. Three sites along the main thrust were chosen to investigate deformation and mineralogy of fault rocks. In all three sites, deformation took place at shallow depths (less than $2 \mathrm{~km}$ ) according to the geometric reconstruction and paleothermometry, showing some features probably due to frictional heating. The magnetic fabrics are related to shear deformation in the fault rocks with different relationships between the magnetic lineation and transport direction: parallel or perpendicular, depending on the amount of shear and also on the lithology of fault rocks. Magnetic lineation is usually contained within the tectonic foliation (instead of shear) planes. In two out of the three analyzed sites, the transport direction is NNW, and NE in the third, easternmost site, thus indicating partitioning of deformation between different thrust surfaces. Paleomagnetism applied to fault rocks indicates that when a significant amount of shear is involved, paleomagnetic vectors resulting from remagnetization of fault rocks approach the transport direction, with the two possible polarities, either contained within the shear or the foliation planes.

Acknowledgments The authors thank Sylvia Gracia for her help in measuring with the KLY3S susceptibility meter, and Manuel Tricas for thin-section preparation. The authors also acknowledge the use of Servicio General de Apoyo a la Investigación-SAI, Universidad de Zaragoza (Servicio de Preparación de Rocas y Materiales Duros, and Servicio de Líquidos Criogénicos). This study has been financed by the Research Project UZ2012-CIE-11 of the University of Zaragoza and the Research Projects CGL2013-42670-P and CGL2012-38481 of the MINECO (Ministerio de Economía y Competitividad of Spain). The authors acknowledge the careful and constructive revisions from Manuel Sintubin and Jean Luc Bouchez, who helped to strongly improve a former version of the manuscript.

\section{References}

Aldega L, Corrado S, Grasso M, Maniscalco R (2007) Correlation of diagenetic data from organic and inorganic studies in the Apenninic-Maghrebian fold-and-thrust belt: a case study from Eastern Sicily. J Geol 115:335-353

Aldega L, Corrado S, Di Paolo L, Somma R, Maniscaldo R, Balestrieri ML (2011) Shallow burial and exhumation of the Peloritani Mountains (NE Sicily, Italy): insight from paleothermal and structural indicators. Geol Soc Am Bull 123:132-149

Allmendinger RW, Cardozo NC, Fisher D (2013) Structural geology algorithms: vectors \& tensors. Cambridge University Press, Cambridge

Alonso JL (1987) Sequences of thrusts and displacement transfer in the superposed duplexes of the Esla Nappe Region (Cantabrian Zone, NW Spain). J Struct Geol 9(8):969-983

Alsop GI (2009) Unravelling patterns of folding in high-strain zones. Trab Geol 29:74-77

Aranguren A, Cuevas J, Tubía JM (1996) Composite magnetic fabrics from S-C mylonites. J Struct Geol 18:863-869

Avouac JP, Tapponnier P, Bai M, You H, Wang G (1993) Active thrusting and folding along the northern Tien Shan and late Cenozoic rotation of the Tarim relative to Dzungaria and Kazakhstan. J Geophys Res Solid Earth 98(4):6755-6804 (1978-2012)

Bailey RC, Halls H (1978) The method of converging remagnetization circles: extension to in-clude stable endpoints and error analysis. EOS Trans AGU 59(12): 1037

Balsamo F, Aldega L, De Paola N, Faoro I, Storti F (2014) The signature and mechanics of earthquake ruptures along shallow creeping faults in poorly lithified sediments. Geology 42:435-438

Barrier L, Nalpas T, Gapais D, Proust JN, Casas A, Bourquin S (2002) Influence of syntectonic sedimentation on thrust geometry. Field examples from the Iberian Chain (Spain) and analogue modelling. Sed Geol 146(1-2):91-104

Bigi S (2006) An example of inversion in a brittle shear zone. J Struct Geol 28(3):431-443

Bigi S, Milli S, Corrado S, Casero P, Aldega L, Botti F, Moscatelli M, Stanzione O, Falcini F, Marini M, Cannata D (2009) Stratigraphy, structural setting and burial history of the Messinian Laga Basin in the context of Apennine foreland basin system. J Mediterr Earth Sci 1:61-84 
Borradaile GJ (1997) Deformation and paleomagnetism. Surv Geophys 18(4):405-436

Bustin RM, Barnes MA, Barnes WC (1990) Determining levels of organic diagenesis in sediments and fossil fuels. In: Mcllreath IA, Morrow DW (eds) Diagenesis. Geological Association of Canada, Toronto, pp 205-226

Calamita F, Satolli S, Turtu A (2012) Analysis of thrust shear zones in curve-shaped belts; deformation mode and timing of the Olevano-Antrodoco-Sibillini thrust (Central/Northern Apennines of Italy). J Struct Geol 44:179-187

Capote R, Muñoz JA, Simón JL, Liesa CL, Arlegui LE (2002) Alpine tectonics I: the Alpine system north of the Betic Cordillera. In: Gibbons W, Moreno T (eds) The geology of Spain. The Geological Society, Bath, pp 367-400

Cardozo N, Allmendinger RW (2013) Spherical projections with OSXStereonet. Comput Geosci 51:193-205

Caricchi C, Aldega L, Barchi MR, Corrado S, Grigo D, Mirabella F, Zattin M (2015) Exhumation patterns along shallow low-angle normal faults: an example from the Altotiberina active fault system (Northern Apennines, Italy). Terra Nova 27(4):312-321

Casas AM, Faccenna C (2001) Tertiary compressional deformation of the Iberian plate. Terra Nova 13:281-288

Casas AM, Simón JL, Seron FJ (1992) Stress deflection in a tectonic compressional field; a model for the northwestern Iberian Chain, Spain. J Geophys Res 97(B5):7183-7192

Casas AM, Villalaín JJ, Soto R, Gil A, del Río P, Fernández G (2009) Multidisciplinary approach to an extensional syncline model for the Cameros Basin (N Spain). Tectonophysics 470:3-20

Casas-Sainz AM (1992) El frente norte de las Sierras de Cameros: estructuras cabalgantes y campo de esfuerzos. Tesis doctoral, Universidad de Zaragoza. Instituto de Estudios Riojanos, Zubía $4, \mathrm{p} 220$

Casas-Sainz AM (1993) Oblique tectonic inversion and basement thrusting in the Cameros Massif (Northern Spain). Geodin Acta 6-3:202-216

Casas-Sainz A, Gil-Imaz A (1998) Extensional subsidence, contractional folding and thrust inversion of the Eastern Cameros Massif, northern Spain. Geol Rundsch 86:802-818

Casas-Sainz AM, Simón-Gómez JL (1992) Stress-field and thrust kinematics-a model for the tectonic inversion of the Cameros Massif (Spain). J Struct Geol 14(5):521-530

Chadima M, Hrouda F (2006) Remasoft 3.0 a user-friendly paleomagnetic data browser and analyzer. Trav Géophys XXVII:20-21

Chadima M, Hrouda F (2009) Cureval 8.0: thermomagnetic curve browser for windows. Agico, Inc, Brno

Chadima M, Jelinek V (2009) Anisoft 4.2: anisotropy data browser for windows. Agico, Inc, Brno

Cogné JP, Perroud H (1985) Strain removal applied to paleomagnetic directions in an orogenic belt: the Permian red slates of the Alpes Maritimes, France. Earth Planet Sci Lett 72(1):125-140

Corrado S, Invernizzi C, Aldega L, D'Errico M, Di Leo P, Zattin M (2010) Testing the validity of organic and inorganic thermal indicators in different tectonic settings from continental subduction to collision: the case history of the Calabria-Lucania border (southern Apennines, Italy). J Geol Soc 167:985-999

Cortés Gracia AL, Casas Sainz AM (1997) Pliegues flexurales asociados al cabalgamiento de la Sierra de la Demanda en el Cerro Peñalba (La Rioja). Geogaceta 21:85-88

Coubal M, Adamovic J, Malek J, Prouza V (2014) Architecture of thrust faults with alongstrike variations in fault-plane dip: anatomy of the Lusatian Fault, Bohemian Massif. J Geosci 59(3):183-208

De Graciansky PC, Dardeau G, Lemoine M, Tricart P (1989) The inverted margin of the French Alps and foreland basin inversion. Geol Soc Lond Spec Publ 44(1):87-104
De Vicente G (2004) Estructura alpina del Antepaís Ibérico. In: Vera JA (ed) Geología de España. SGE-IGME, Madrid, pp 587-634

Debacker TN, Robion P, Sintubin M (2004) The anisotropy of magnetic susceptibility (AMS) in low-grade, cleaved pelitic rocks: influence of cleavage/bedding angle and type and relative orientation of magnetic carriers. Geol Soc Lond Spec Publ 238(1):77-107

Debacker TN, Hirt AM, Sintubin M, Robion P (2009) Differences between magnetic and mineral fabrics in low-grade, cleaved siliciclastic pelites; a case study from the Anglo-Brabant deformation belt (Belgium). Tectonophysics 466(1-2):32-46

Debacker TN, Sintubin M, Robion P (2010) On the use of magnetic techniques for stratigraphic purposes: examples from the Lower Palaeozoic Anglo-Brabant Deformation Belt (Belgium). Geol Belgica 13:333-350

Dunlop DJ, Özdemir Ö (1997) Rock magnetism. Fundamentals and frontiers. In: Edwards D (ed) Cambridge studies in magnetism. Cambridge University Press, Cambridge, p 253

Durand B (1980) Sedimentary organic matter and kerogen. Definition and quantitative importance of kerogen. In: Durand B (ed) Kerogen: insoluble organic matter from sedimentary rocks. Editions Technip, Paris, pp 13-33

Elliot D (1976) The energy balance and deformation mechanisms of thrust sheets. Philos Trans R Soc 283:289-312

Erslev EA (1986) Basement balancing of Rocky Mountain foreland uplifts. Geology 14(3):259-262

Fauconnier J, Stünitz H, Rosenberg C, Labrousse L, Jolivet L (2014) Étude expérimentale de la fusion partielle sur la rhéologie et la microstructure de la croûte continentale. RST Pau Résum $3(8): 26$

Fernández-Lozano J (2012) Cenozoic deformation of Iberia: a model for intraplate mountain building and basin development based on analogue modelling. Ph.D. thesis, Utrecht Studies in Earth Sciences 013, p 173

Fernández-Lozano J, Sokoutis D, Willingshofer E, Cloetingh S, De Vicente G (2011) Cenozoic deformation of Iberia; a model for intraplate mountain building and basin development based on analogue modeling. Tectonics 30(1):TC1001

Fisher RA (1953) Dispersion on a sphere. Proc R Soc Lond A 217:295-305

García-Lasanta C, Oliva-Urcia B, Román-Berdiel T, Casas AM Pérez-Lorente F (2013) Development of magnetic fabric in sedimentary rocks: insights from early compactional structures (ECS). Geophys J Int 194(1):182-199

Grasemann B, Fritz H, Vannay J-C (1999) Quantitative kinematic flow analysis from the Main Central Thrust Zone (NW-Himalaya, India): implications for a decelerating strain path and the extrusion of orogenic wedges. J Struct Geol 21:837-853

Guimerà J, Alonso I, Mas J R (1995) Inversion of an extensionalramp basin by a newly formed thrust: the Cameros basin $(\mathrm{N}$ Spain). In: Buchanan JG, Buchanan PG (eds) Basin inversion. Geol Soc Special Publication 88, pp 433-453

Guimerà J, Más R, Alonso A (2004) Intraplate deformation in the NW Iberian Chain: mesozoic extension and contractional inversion. J Geol Soc Lond 16:291-303

Haerinck T, Wenk HR, Debacker TN, Sintubin M (2015) Preferred mineral orientation of a chloritoid-bearing slate in relation to its magnetic fabric. J Struct Geol 71:125-135

Haines SH, van der Pluijm BA (2012) Patterns of mineral transformations in clay gouge, with examples from low-angle normal fault rocks in the western USA. J Struct Geol 43:2-32

Hirono T, Lin W, Yeh EC, Soh W, Hashimoto Y, Sone H, Matsubayashi O, Aoike K, Ito H, Kinoshita M, Murayama M, Song SR, Ma K-F, Hung J-H, Wang C-Y, Tsai Y-B (2006) High magnetic susceptibility of fault gouge within Taiwan Chelungpu 
fault: nondestructive continuous measurements of physical and chemical properties in fault rocks recovered from Hole B, TCDP. Geophys Res Lett 33(15):4,L15303

Hirt AM, Gehring A (1991) Thermal alteration of the magnetic mineralogy in ferruginous rocks. J Geophys Res 96:9947-9954

Hrouda F, Jélinek V, Zapletal K (1997) Refined technique for susceptibility resolution into ferromagnetic and paramagnetic components based on susceptibility temperature-variation measurement. Geophys J Int 129:715-719

Jacob H, Hiltmann W (1985) Disperse bitumen solids as an indicator for migration and maturity within the scope of prospecting for petroleum and natural gas - a model for NW Germany: DGMK. Forschungsbericht 267:1-54

Jagodzinski H (1949) Eindimensionale Fehlordnung in Kristallen und ihr Einfluss auf die Röntgen Interferenzen. Acta Crystallogr A 2:201-207

Jelinek V (1977) The statistical theory of measuring anisotropy of magnetic susceptibility of rocks and its application. Geofyzika, Brno, pp 1-88

Jelinek V (1978) Statistical processing of anisotropy of magnetic susceptibility measured on groups of specimens. Stud Geoph Geod 22:50-62

Jelinek V (1981) Characterization of the magnetic fabric of rocks. Tectonophysics 79:63-70

Jones BF, Galan E (1988) Palygorskite-sepiolite. In: Bailey SW (ed) Hydrous phyllosilicates (exclusive of micas). Rev in Min 19, Min Soc Amer, Washington, p 698

Kirschvink JL (1980) The least-squares line and plane and the analysis of paleomagnetic data. Geophys J R Astr Soc 62:669-718

Kley J, Voigt T (2008) Late Cretaceous intraplate thrusting in central Europe: effect of Africa-Iberia-Europe convergence, not Alpine collision. Geology 36(11):839-842

Kligfield R, Lowrie W, Hirt A, Siddans AWB (1983) Effect of progressive deformation on remanent magnetization of Permian redbeds from the Alpes Maritimes (France). Tectonophysics 98(1):59-85

Lattard D, Engelmann R, Kontny A, Suerzapf U (2006) Curie temperatures of synthetic titanomagnetites in the $\mathrm{Fe}-\mathrm{Ti}-\mathrm{O}$ system: effects of composition, crystal chemistry, and thermomagnetic methods. J Geophys Res 111:B12S28. doi:10.1029/200 6JB004591

Liesa CL, Simón JL (2009) Evolution of intraplate stress fields under multiple remote compressions: the case of the Iberian Chain (NE Spain). Tectonophysics 474:144-159

Lister GS, Snoke AW (1984) S-C mylonites. J Struct Geol 6:617-638

Lowrie W, Hirt AM, Kligfield R (1986) Effects of tectonic deformation on the remanent magnetization of rocks. Tectonics 5(5):713-722

Lüneburg CM, Lampert SA, Hermann I, Lebit D, Hirt AM, Casey M, Lowrie W (1999) Magnetic anisotropy, rock fabrics and finite strain in deformed sediments of SW Sardinia (Italy). Tectonophysics 307:51-74

Martín-Hernández F, Ferré EC (2007) Separation of paramagnetic and ferromagnetic anisotropies: a review. J Geophys Res Solid Earth 112(B3):B03105

Mas JR, Alonso A, Guimera J (1993) Evolución tectonosedimentaria de una cuenca extensional intraplaca: la cuenca finijurásicaeocretácica de Los Cameros (La Rioja-Soria). Rev Soc Geol Esp 6(3-4):129-144

Mata MP, Casas AM, Canals A, Gil A, Pocovi A (2001) Thermal history during Mesozoic extension and tertiary uplift in the Cameros Basin, Northern Spain. Basin Res 13:91-111

Mata MP, Villalaín JJ, Casas AM (2006) Mineralogía magnética en rocas mesozoicas remagnetizadas de la Cordillera Ibérica (Sinclinal de Villavelayo-Sierra de la Demanda). MACLA (ISSN:1885-7264) 6, pp 301-303
Mertainen S, Karell F (2012) Palaeomagnetic and AMS studies on Satulinmäkiand Koijärvi fault and shear zones. Geol Surv Finland Spec Pap 52:195-226

Moore DM, Reynolds RC Jr (1997) X-ray diffraction and the identification and analysis of clay minerals. Oxford University Press, Oxford

Moreno E, Homberg C, Schnyder J, Person A, du Peloux A, Dock P (2014) Fault imprint in clay units: magnetic fabric, structural and mineralogical signature. EGU General Assembly 2014. Geophysical Research Abstracts 16, EGU2014-15479

Muñoz JA, Coney P, McClay K, Evenchick C (1997) Discussion on syntectonic burial and post-tectonic exhumation of the southern Pyrenees foreland fold-thrust belt. J Geol Soc Lond 154:361-365

Muñoz-Jiménez A, Casas-Sainz AM (1997) The Rioja Trough (N Spain): tectosedimentary evolution of a symmetric foreland basin. Basin Res 9-1:65-85

Nieto F, Mata MP, Bauluz B, Giorgietti G, Árkai P, Peacor DR (2005) Retrograde diagenesis, a widespread process on a regional scale. Clay Miner 40:93-104

Oliva-Urcia B, Pueyo EL (2007) Rotational basement kinematics deduced from remagnetized cover rocks (Internal Sierras, southwestern Pyrenees). Tectonics 26:TC4014

Oliva-Urcia B, Pueyo EL, Larrasoaña JC (2008) Magnetic reorientation induced by pressure solution: a potential mechanism for orogenic-scale remagnetizations. Earth Planet Sci Lett 265:525-534

Oliva-Urcia B, Larrasoaña JC, Pueyo EL, Gil A, Mata P, Parés JM, Schleicher AM, Pueyo Ó (2009) Disentangling magnetic subfabrics and their link to deformation processes in cleaved sedimentary rocks from the Internal Sierras (west central Pyrenees, Spain). J Struct Geol 31(2):163-176

Oliva-Urcia B, Casas AM, Pueyo EL, Román-Berdiel T, Geissman JW (2010a) Paleomagnetic evidence for dextral strike-slip motion in the Pyrenees during alpine convergence (Mauléon basin, France). Tectonophysics 494(3):165-179

Oliva-Urcia B, Casas AM, Soto R, Villalaín JJ, Kodama K (2010b) A transtensional basin model for the Organyà basin (central southern Pyrenees) based on magnetic fabric and brittle structures. Geophys J Int 184(1):111-130

Oliva-Urcia B, Román-Berdiel T, Casas AM, Pueyo EL, Osácar C (2010c) Tertiary compressional overprint on Aptian-Albian extensional magnetic fabrics, North Pyrenean Zone. J Struct Geol 32:362-376

Omodeo-Salé S, Salas R, Guimerà J, Ondrak R, Mas R, Arribas J, Suárez-Ruiz I, Martinez L (2015) Subsidence and thermal history of an inverted Late Jurassic-Early Cretaceous extensional basin (Cameros, North-central Spain) affected by very lowto low-grade metamorphism. Basin Research. doi:10.1111/ bre. 12142

Ono T, Hosomi Y, Arai H, Takagi H (2010) Comparison of petrofabrics with composite magnetic fabrics of $\mathrm{S}-\mathrm{C}$ mylonite in paramagnetic granite. J Struct Geol 32(1):2-14

Parés JM, Van der Pluijm BA (2002) Phyllosilicate fabric characterization by low-temperature anisotropy of magnetic susceptibility (LT-AMS). Geophys Res Lett. doi:10.1029/2002GL015459

Parés JM, Van Der Pluijm BA, Dinarès-Turell J (1999) Evolution of magnetic fabrics during incipient deformation of mudrocks (Pyrenees northern Spain). Tectonophysics 307:1-14

Pérez-Estaún A, Bastida F, Alonso JL, Marquínez J, Aller J, AlvarezMarrón J, Marcos A, Pulgar JA (1988) A thin-skinned tectonics model for an arcuate fold and thrust belt: the Cantabrian Zone (Variscan Ibero-Armorican Arc). Tectonics 7(3):517-537

Petrovsky E, Kapicka A (2006) On determination of the Curie point from thermomagnetic curves. J Geophys Res 11:B12S27. doi:1 0.1029/2006JB004507 
Pichot T, Nalpas T (2009) Influence of synkinematic sedimentation in a thrust system with two decollement levels; analogue modelling. Tectonophysics 473:466-475

Pollastro RM (1990) The illite/smectite geothermometer-concepts, methodology and application to basin history and hydrocarbon generation. In: Nuccio BF, Barker CE (eds) Application of thermal maturity studies to energy exploration. Society of Economic Paleontologists and Mineralogists, Rocky Mountains Section, pp 1-18

Pomella H (2014) Magnetic fabic of brittle fault rocks. EGU General Assembly 2014. Geophysical Research Abstracts 16, EGU2014-12505

Ramsay JG (1967) Folding and fracturing of rocks. McGraw-Hill Companies, New York

Ramsay JG (1981) Tectonics of the Helvetic nappes. Geol Soc Lond Spec Publ 9(1):293-309

Ramsay JG, Huber MI (1987) The techniques of modern structural geology. Vol 2: folds and fractures. Academic, London, pp 309-700

Ramsay JG, Casey M, Kligfield R (1983) Role of shear in development of the Helvetic fold-thrust belt of Switzerland. Geology 11(8):439-442

Ritcher C, Van der Pluijm BA (1994) Separation of paramagnetic and ferrimagnetic susceptibilities using low temperature magnetic susceptibilities and comparison with high field methods. Phys Earth Planet Inter 82:113-123

Schleicher AM, van der Pluijm BA, Warr LN (2012) Chlorite-smectite clay minerals and fault behavior: new evidence from the San Andreas Fault Observatory at Depth (SAFOD) core. Lithosphere 4(3):209-220

Seillé H, Salas R, Pous J, Guimerà J, Gallart J, Torne M, RomeroRuiz I, Diaz J, Ruiz M, Carbonell R, Mas R (2015) Crustal structure of an intraplate thrust belt: the Iberian Chain revealed by wide-angle seismic, magnetotelluric soundings and gravity data. Tectonophysics 663:339-353

Simón JL, Liesa CL (2011) Incremental slip history of a thrust; diverse transport directions and internal folding of the Utrillas thrust sheet (NE Iberian chain, Spain). Geol Soc Lond Spec Publ 349:77-97

Smithson SB, Brewer J, Kaufman S, Oliver J, Hurich C (1978) Nature of the Wind River thrust, Wyoming, from COCORP deepreflection data and from gravity data. Geology 6(11):648-652

Snoke AW, Tullis J, Todd VR (eds) (1998) Fault-related rocks: a photographic atlas. Princeton University Press, Princeton

Solum JG, van der Pluijm BA (2009) Quantification of fabrics in clay gouge from the Carbonera fault, Sapin and implications for fault behavior. Tectonophysics 475:554-562

Stach E, Mackowsky MT, Teichmüller M, Taylor GH, Chandra D, Teichmuller R (1982) Stach's textbook of coal petrology. Gebrüder Borntraeger, Berlin

Steidtmann JR, Middleton LT (1991) Fault chronology and uplift history of the southern Wind River Range, Wyoming: implications for Laramide and post-Laramide deformation in the Rocky Mountain foreland. Geol Soc Am Bull 103(4):472-485

Trincal V, Charpentier D, Buatier MD, Grobety B, Lacroix B, Labaume P, Sizun J-P (2014) Quantification of mass transfers and mineralogical transformations in a thrust fault (Monte Perdido thrust unit, southern Pyrenees, Spain). Mar Pet Geol 55:160-175

Villalaín JJ, Fernández-González G, Casas AM, Gil-Imaz A (2003) Evidence of a Cretaceous remagnetization in the Cameros Basin (North Spain). Implications for basin geometry. Tectonophysics 377:101-117

Vrolijk P, van der Pluijm BA (1999) Clay gouge. J Struct Geol 21(8):1039-1048

Yonkee WA, Parry WT, Bruhn RL, Cashman PH (1989) Thermal models of thrust faulting: constraints from fluid-inclusion observations, Willard thrust sheet, Idaho-Utah-Wyoming thrust belt. Geol Soc Am Bull 101:304-313

Zheng Y, Davis GA, Wang G, Darby BJ, Hua Y (1998) Major thrust sheet in the Daqing Shan Mountains, Inner Mongolia, China. Sci China (Ser D) 41(5):553-560 